\title{
2. DEFINITION DER QUELLENGRUPPE
}

In den wenigen Arbeiten, die sich bisher mit den Heroldskompendien auseinandergesetzt haben, wurden diese als immer wieder aus verschiedenen Traktaten neu zusammengesetzte Textkompilationen beschrieben, die Texte zum Heroldswesen wie allgemein für die Ausführung seiner Aufgaben notwendiges Wissen beinhalteten. Meist als Gebrauchshandschriften angefertigt, sollten sie vorrangig der eigenen Information wie der Unterweisung ihrer Kollegen und Nachfolger dienen, zu einem geringeren Teil aber auch in Form von Prunkcodices als Werbeträger für das Heroldsamt.

Nicht zuletzt durch den Umstand bedingt, daß es sich um das einzig integral edierte Exemplar einer solchen Textsammlung handelt, prägte bisher vor allem das »Kompendium des Herolds Sicile« deren Bild. Dabei ist die zumeist seiner Verfügbarkeit geschuldete Aufmerksamkeit auch inhaltlich gerechtfertigt, handelt es sich hier doch tatsächlich um die geschlossenste wie ausgereifteste aller uns erhaltenen Überlieferungen dieser Quellengruppe ${ }^{1}$. Dies heißt mit anderen Worten, daß insbesondere diese Kompilation sich als einschlägiges Beispiel eignen mag, die charakteristischen Grundlinien der Heroldskompendien genauer zu veranschaulichen. Diese können sodann als Ausgangspunkt für die Suche nach weiteren Exemplaren dieser Quellengruppe dienen, um sie anschließend näher in ihr Überlieferungsumfeld einzuordnen.

Dabei soll aber nicht nur nach den Inhalten des »Kompendiums des Herolds Sicile« und den ihm zugrundeliegenden Intentionen gefragt werden. In der neueren Forschung zwar öfters zitiert, aber noch nie eingehender hinterfragt, sind zugleich auch die wenigen Spuren seiner Entstehung und Überlieferung nachzuverfolgen. Hierbei werden zugleich jene Probleme anschaulich, die für die Arbeit mit den Heroldskompendien insbesondere in Bezug auf deren Datierung, Zuweisung und Überlieferung so charakteristisch sind.

\subsection{Das »Kompendium des Herolds Sicile« als Muster}

\subsubsection{Entstehung}

Bisher ist bekannt, daß der Text an sich zwischen den Jahren 1435 und 1437 von einem Herold Sicile kompiliert worden sein muß, der sich in Unterschriften am Ende einzelner Traktate als solcher selbst nennt ${ }^{2}$. Bereits am Beginn des Prologes führt er zu seiner Person aus:

${ }^{1}$ Eine entsprechende Bewertung auch des Inhaltes und der Struktur des »Kompendiums des Herolds Sicile« findet sich bereits bei MeLVILLE, Brief, S. 73.

2 Vgl. z.B. Roland (Hg.), Parties inédites, z.B. S. 40, 127 u. a. 
Je, hérault à très-puissant roy Alphonse d'Arragon, de Sicille, de Valence, de Maillorque, de Corseghe et de Sardaigne, comte de Barselone, etc., à present et de longtemps ayans domicille et la résidence en la bonne ville de Mons en Hainau ${ }^{3}$.

Gonzalès Decamps gelang es, die Person des Herolds Sicile zu identifizieren und den Zeitpunkt seines Todes näher zu bestimmen. Mit bürgerlichem Namen hieß Sicile demnach Jean Courtois. Dies läßt sich aus mehreren Dokumenten vom 8. August 1437 erschließen, in welchen eine gewisse Jehanne Maillotte als vesve de Jehan Courtois dit Sezille le hiraut ${ }^{4}$ bezeichnet wird. Ein Eintrag in den Rechnungen der Massarderie de Mons belegt darüber hinaus, daß Sicile bereits vor dem 11. Juni 1437 verstorben sein muß, er an diesem Kompendium daher nur vor diesem Datum gearbeitet haben kann 5 .

Ort und Jahr seiner Geburt sind unbekannt. Nach den Darstellungen von Gonzalès Decamps diente er zuerst Peter I. von Luxemburg, Grafen von Saint-Pol und Brienne, als Herold unter dem Namen Enghien. Hierfür scheint auch eine Miniatur am Beginn seines Heroldskompendiums zu sprechen, wo er mit dem Wappen von Engien in seiner Hand abgebildet ist ${ }^{6}$. Als er Peter von Luxemburg zu dessen Besitzungen in Sizilien begleitete, wäre er dann, so Decamps, zuerst als Herold Jerusalem in den Dienst des Herzogs Ludwig von Anjou, (Titular-)König von Jerusalem, übergegangen, um bald darauf als Herold Sicile dessen Kontrahenten König Alphons V. von Aragon zu dienen.

Als Herold des aragonesischen Königs für Sizilien, wo dieser zumindest für den neapolitanischen Teil seine Rechte noch nicht hatte endgültig durchsetzen können, war Sicile seit längerer Zeit in Mons ansässig, wo er vor 1429 ein Haus kaufte und das Bürgerrecht besaß. Nach dem Beginn des von ihm überlieferten Heroldskompendiums erhielt er bald auch das Amt des Wappenmarschalls des Hennegaus übertragen, worauf er in der Unterschrift des ersten Traktates der Kompilation aufmerksam macht: Sicile, hérault, depuis le commencement de cestui livre mareschal d'armes du pays de Hainau?

Die darauffolgenden Traktate unterschreibt er daraufhin nur noch mit Sicile, hérault, marissal de Hainau ${ }^{8}$. Zur Datierung des Textes ist diese Notiz jedoch wenig tragend, auch wenn Decamps für 1430 einen Rechnungsbeleg aufführt, der einen Wappenmarschall des Hennegau unter dem Namen Enghien belegt ${ }^{9}$. Dabei geht er davon aus, daß es sich hier um den Herold Sicile handelt, der nur unter seinem alten, in seiner Heimat vielleicht bekannteren Amtsnamen geführt wurde.

3 Ibid., S. 1.

4 DeCAmps, Les hérauts, hier die Dokumente II und III, das Zitat ibid., S. 233. Zu Sicile vgl. darüber hinaus MATTHIEU, Sicile (Jehan Courtois, dit).

5 Ein Beleg aus den Rechnungen der Massarderie de Mons für 1436/37 bezeugt ihn indirekt als verstorben: De la vefve Sezille le herault, qui, le xje jour de ce mois (juin), s'en alla demorer à Tournoay, rechupt ... vj S. (zitiert nach DECAMPS, Les hérauts, S. 223 m. Anm. 2). 6 Eine Abbildung dieser Miniatur findet sich auf dem Vorsatzblatt der Edition des Kompendiums, Roland (Hg.), Parties inédites.

7 Vgl. ibid., S. 40.

8 Vgl. ibid., S. 61 oder auch S. 127.

9 Vgl. Decamps, Les hérauts, S. 219, Anm. 4. 
Wenn Decamps in der betreffenden Funktion dann aber auch noch für das Jahr 1425 einen Jerusalem belegt und diesen ebenfalls mit Sicile identifiziert, dessen Amtsantritt als Wappenmarschall des Hennegau somit vor das Jahr 1425 legend, so ist dies zuviel der Spekulation. Viel wahrscheinlicher ist, daß Sicile erst nach 1430 Wappenmarschall wurde und es sich bei den erwähnten Herolden Jerusalem und Enghien um andere Personen handelte. Dann aber sind die obigen Bemerkungen zu dessen Biographie respektive zur Abfolge seiner Herren zu revidieren, baute Decamps seine Ausführungen doch allein auf diese äußerst fragwürdige Konstruktion auf ${ }^{10}$.

Geht man zurück zu den Fakten, so läßt sich festhalten, daß Sicile König Alphons V. erst nach 1416, dem Jahr seiner Thronbesteigung, als Herold gedient haben kann, er bereits vor 1429 in Mons ansässig war, aber erst nach 1430 zum Wappenmarschall aufstieg und vor Juni 1437 starb $^{11}$.

Wenn der Entstehungszeitraum für den Text des Kompendiums weiter oben noch genauer auf die Jahre 1435-1437 beschränkt wurde, so verweist dies auf einen weiteren textinternen Anhaltspunkt, der für die Datierung bisher stets herangezogen wurde. Bereits im Prolog seines Kompendiums kündigte Sicile an, in dessen zweitem Teil auch den Wortlaut mehrerer Suppliken wiederzugeben: Aulcunes supplications adreschans aux roys, princes et nobles seigneurs du royaulme de France ${ }^{12}$.

Nimmt man nun die beiden im Text enthaltenen Suppliken hinzu, deren zweite aus dem Jahre 1435 stammt, so könnte man meinen, daß die im Prolog verwendete Bezeichnung »aulcunes« ebendiese beiden meint, der Prolog folglich auch frühestens aus dem Jahre 1435 stammen kann. Dies scheint zwar möglich, ist aber nicht zwingend, da die hier enthaltene erste Supplik sämtlichen anderen Überlieferungen folgend eigentlich aus zwei Suppliken besteht, die bei Sicile nur eben nicht getrennt wiedergegeben wurden ${ }^{13}$. Diese Lesart scheint umso wahrscheinlicher, sind doch die ersten beiden Suppliken ihrem gemeinsamen Titel nach au roy et princes de France ${ }^{14}$ gerichtet, während jene von 1435 à tous empereurs, rois, ducs, princes, barons, comtes, nobles, chevaliers et escuyers ${ }^{15}$ adressiert war und dem burgundischen Herzog Philipp dem Guten übergeben wurde. Es scheint demnach möglich, daß diese Bittschrift erst später in die vorliegende Textsammlung aufgenommen wurde, oder aber während deren Kompilation durch den Herold Sicile selbst. Der Inhalt dieser Supplik nimmt teils wörtlich den ersten Teil des Kompendiums zur Geschichte des Heroldswesens auf, die in dieser Weise nur hier überliefert ist. In der Rubrik der Supplik von Sicile selbst wurde ver-

10 Vgl. ibid., S. 219 mit Anm. 4.

${ }^{11}$ Im Jahr 1441 erscheint dann auch ein anderer Herold mit dem Amtsnamen Oranges in der Funktion des Wappenmarschalls des Hennegau, vgl. Heraudica, sources, no 12549.

12 Roland (Hg.), Parties inédites, S. 2.

13 Für die weiteren Überlieferungen der beiden Suppliken siehe unten, Anhang, Kap. 6.2.1.4.

14 Roland (Hg.), Parties inédites, S. 107.

15 Ibid., S. 116. 
merkt, daß er es war, der diese lettres de salutation concluantz en supplication in Begleitung zahlreicher Herolde dem Herzog präsentierte ${ }^{16}$. Der Beginn seiner Arbeit an dem vorliegenden Kompendium sollte daher vor 1435 gelegen haben.

Das »Kompendium des Herolds Sicile«, wie es der Edition zugrunde lag, ist nur als Fragment überliefert. Ob Sicile seine Arbeit bis zu seinem Tod vor der Jahresmitte 1437 tatsächlich abschließen konnte, kann letztgültig nicht geklärt werden. Père Roland stellte in seiner Edition des Textes bereits richtig fest, daß es sich bei der von ihm verwendeten Handschrift (Paris, BnF, fr. 387) um keinen Autographen, sondern um eine Kopie handelte. Aber bis auf eine kurze Notiz in einer Fußnote bei Anthony Richard Wagner ${ }^{17}$ wurde dabei bisher übersehen, daß diese Kopie auch erst einige Zeit nach der Niederschrift des Textes und damit nach dem Tod Siciles entstanden sein konnte. Mehrere Gründe sprechen dafür, daß zwischen der Arbeit Siciles und der Anfertigung der vorliegenden Handschrift mindestens ein Vierteljahrhundert liegt und der überlieferte Text nicht die originale Fassung Siciles wiedergibt ${ }^{18}$.

Einen Anhaltspunkt hierfür bietet die gleich zweifache Titulierung des burgundischen Herzogs Philipp des Guten als Herzog von Luxemburg ${ }^{19}$. So geschehen unter anderem in der Überschrift der bereits erwähnten Supplik von 1435, als deren Überbringer sich Sicile im gleichen Atemzug selbst nennt ${ }^{20}$. Während Sicile jedoch noch vor der Jahresmitte 1437 verstorben sein muß, war es erst 1441, daß der Burgunder Herzog die Rechte an Luxemburg erwarb, die er auch erst zwei Jahre später militärisch durchsetzen konnte.

Doch insbesondere der Obsequientraktat, der die vorliegende Handschrift fragmentarisch abschließt und auch in den Inhaltsangaben des Prologes nicht aufgeführt ist, kann erst aus der Zeit nach 1461 stammen. Vergleicht man die darin aufgeführten Ordonnanzen mit den königlichen Leichenzügen des 15. Jahrhunderts, so entsprechen sie genau denen von 1461, anläßlich der Bestattung Karls VII. Zu allen anderen hingegen, ob für Karl VI. (1422), Ludwig XI. (1483) oder Karl VIII. (1498), bestehen erhebliche Abweichungen ${ }^{21}$. Ungewöhnlich dabei ist

16 Vgl. Roland (Hg.), Parties inédites, S. 116. Daß Sicile in Arras anwesend war, geht aus mehreren Aufzählungen der in Arras anwesenden Herolde hervor, vgl. Contamine, Aperçus nouveaux, S. 593.

$17 \mathrm{Vgl}$. WAGneR, Heralds of England, S. 40, Anm. 5.

$18 \mathrm{Zu}$ weiteren Besonderheiten der Überlieferung des »Kompendiums des Herolds Sicile«, welche noch immer einige Fragen aufwerfen, siehe noch unten, Kap. 3.2.4.

19 Vgl. Roland (Hg.), Parties inédites, S. 116 und S. 202. Einen Hinweis auf diese Tatsache gibt, eher beiläufig und mit einem unklaren Verweis auf Paul Adam-Even, WAGNER, Heralds of England, S. 40, Anm. 5, hier aber nur in bezug auf die Titulatur des Herzogs innerhalb der kurzen »Anleitung zur Ausrufung des largesse-Dankes« (vgl. RoLAND [Hg.], Parties inédites, S. 202).

20 Lettres de salutation concluantz en supplication [...] présentées à très excellent, très hault, très puissant et très redoubté prince, monseigneur Philippe, par la grâce de Dieu, duc de Bourgogne, de l'Otrilz [i.e. Lothier; T.H.], de Brabant, de Lembourg et de Luxembourg [...] par moy Sicille, hérault dessusdit, acompaignié de pluiseurs roys d'armes et héraulx, là estant au nombre de vinqt-huit (RoLAND [Hg.], Parties inédites, S. 116).

21 Vgl. GIESEY, »Le roi ne meurt jamais«, u. a. mit einer hilfreichen Übersicht S. $317 \mathrm{f}$. 
die Anordnung des unvermittelt abbrechenden Textes am Ende der zweispaltigen Handschrift. Hier sind in der ersten Spalte nur 22 von 48 Zeilen ausgefüllt, woraufhin der Text die Spalte wechselt und nach vier weiteren Zeilen endet. Der Rest der Seite wie drei weitere Folio im Anschluß blieben unbeschrieben. Es mag also sein, daß an dieser Stelle eine Miniatur eingefügt werden sollte, was wiederum bedeuten könnte, daß bereits die Vorlage der vorliegenden Handschrift den Traktat zu den königlichen Obsequien enthielt und auch diese schon nicht dem Original Siciles entsprach.

Bei der Handschrift, die der Edition des Sicile-Textes zugrunde lag, handelt es sich daher um eine Kopie, die erst mehrere Jahrzehnte nach dem ihr zugrundeliegenden Text, mindestens aber nach 1461 entstand, dem darüber hinaus teils erhebliche Modifikationen beigebracht wurden. Dabei sei noch einmal auf die zumindest im ersten Teil der Handschrift enthaltenen Miniaturen verwiesen und damit auch auf jene Abbildungen, welche sicherlich den Autor des Kompendiums wiedergeben sollten. Während deren erste später nur aufgeklebt wurde, ist auch zur Herkunft der anderen nichts Sicheres zu sagen. Denn an jenen Aussparungen für die noch unausgeführten Miniaturen in der zweiten Hälfte des Manuskriptes finden sich Reste eingeklebter Illuminatorenanweisungen, welche relativ sicher von Jacques Le Boucq (†1572) stammen. In dessen Händen befand sich das Manuskript im 16. Jahrhundert. Er selbst war als Herold des Ordens vom Goldenen Vlies, aber auch als Illuminator bekannt ${ }^{22}$.

Bei all den offenen Fragen zu der der Edition zugrundeliegenden Handschrift und deren Text scheint dennoch sicher zu sein, daß zumindest der Wortlaut des Prologes und die ersten Traktate von Sicile selbst stammen bzw. zusammengetragen wurden. Auf diese soll im folgenden näher eingegangen werden.

\subsubsection{Inhalt und Intention}

In seinem Prolog gibt uns Sicile einen kurzen Einblick in Entstehung und Intention seines Kompendiums und entwirft einen Überblick über Konzeption und Inhalt. Wenn also auch das Kompendium an sich möglicherweise unvollendet blieb oder nur in veränderter Form überliefert wurde, so informiert uns doch der Prolog über Siciles ursprünglichen Plan und seine Absichten für dieses Unternehmen. In den ersten Zeilen heißt es sogleich:

Je, hérault à très-puissant roy Alphonse d'Arragon, [...] ay par pluiseurs fois prétendu de tant enquérir, entendre et sçavoir à l'aide de Dieu, de tous mes seigneurs, princes, chevaliers et escuyers, et de tous mes frères, amis et compagnons, roys d'armes et héraulx, que je puisse tant faire aucunement par vrais et raisonnables entendements, que si on me demandoit ou parloit de mon office par quelque estat que ce fust à moy appartenant, de sçavoir en respondre par si bonne manière qu'on feust de moy content, et ay à l'aide de Dieu et de tous mes seigneurs et amis fait et ordonné ce présent livre ${ }^{23}$.

22 Vgl. das zu dieser Handschrift im IRHT (Paris) vorhandene Dossier. Zu Jacques Le Boucq siehe noch unten, S. 134.

23 Roland (Hg.), Parties inédites, S. 1. 
Sicile war also in besonderer Weise dazu befähigt, über das Heroldsamt zu berichten. Was uns hier vorliegt, sind mithin die Ergebnisse seiner Nachforschungen bei Fürsten, Rittern und Kollegen, die er mit Hilfe seiner Herren und Freunde in diesem Buch zusammenzufassen sucht. Es ist ihm also - auch in Abgrenzung zu seinen restlichen Heroldskollegen - ein besonderes Interesse an seinem eigenen Amt zu unterstellen und gleichsam das Bedürfnis, das hierbei gesammelte Wissen auch $\mathrm{zu}$ verbreiten. In der Widmung des ersten Traktates, welcher sich mit den Ursprüngen des Heroldswesens beschäftigt, wird dies noch deutlicher:

De touttes lesquelles choses, je ay entrepris d'en faire ung petit traittié et enseignement, à celle fin, que par vous, mes dessusditz très chiers et bien amés frères, vrais amis et léaulx compaignons, il en soit vraye mémoire perpétuelle. Et aussy pour ce je voy et cognoy assés que pluiseurs haults, nobles et puissants roys, princes et seigneurs, pour l'augmentation d'eulx et de leurs affaires et pour accroistre et veullant honnourer ledit office, font pluiseurs jones et aultres porsievans d'armes, clercz ou non clercz, au los de leur noble conseil, et aulcuns font héraulx ou roys d'armes qui ne leur enquièrent mie, ou font enquérir se ils sont bien advertis de ce que ilz entreprendent, ne s'ilz sçavent que ce veult estre à dire roy d'armes, hérault ou poursievant, mais les font les aulcuns bien voluntairement; dont par le moyen de cestuy traittié et enseignement que j'ay entrepris au plaisir de Dieu à faire et accomplir, ilz en porront estre advertis de aulcune petitte partie en commencement, que pour en sçavoir la perfection ${ }^{24}$.

Ihm geht es also darum, Wissen zur Geschichte seines Amtes zu sammeln, zu bewahren und seinen Kollegen im Heroldsamt zur Verfügung zu stellen. Ein besonderes Anliegen scheint ihm hierbei zu sein, damit auch jene zu erreichen, die wohl in größerer Zahl, wie er schreibt - zu diesem Amt gekommen sind, ohne über die, wie er meint, hierfür notwendigen Kenntnisse zu verfügen. Teil seiner Absicht ist es daher, unter seinen Kollegen einen bestimmten Standard an Wissen zu seinem Amt und eine bestimmte Einstellung zu diesem zu verbreiten, die er im folgenden aus dessen Geschichte heraus zu begründen sucht.

Dieser erste Teil, wie auch der gesamte Text des »Kompendiums des Herolds Sicile« richtet sich somit vorrangig an die Mitglieder des office d'armes. Das Wissen, was hier vermittelt wird, sollte dabei jedem Herold geläufig sein. Denn in dieser Weise beschreibt Sicile am Ende des Prologes die hierin versammelten Unterweisungen:

Lesquelles choses dessusdittes sont bien licites et raisonnables de sçavoir à tous nobles roix d'armes, héraulx et officiers d'armes, qui se veullent applicquer, comme ilz doivent, à deuement excercer ladite noble office d'armes ${ }^{25}$.

Den Inhalt dieser Heroldsunterweisung unterteilt er dabei in folgende vier Bücher $^{26}$ :

- Das erste Buch umfasse, wie das Amt gegründet wurde, wer die ersten Gründer waren, warum es zum ersten Mal unterging, wann und durch wen es wieder aufgerichtet wurde und wie es ein zweites Mal versagte; den Brief der Römer,

24 Ibid., S. 8.

25 Ibid., S. 3.

26 Vgl. ibid., S. 2 f. 
den sie während der Belagerung von Karthago an Scipio bezüglich der zwölf Herolde sandten, die sie dort ernannten und die Bestimmungen, die darin enthalten sind, wie die Bestimmungen anderer Könige, Fürsten und Herolde, wie sie heute noch gültig seien; ein Traktat über die Gründung des Heroldsamtes durch Julius Caesar.

- Das zweite Buch enthält einige Suppliken an die Könige, Fürsten und Herren von Frankreich; den Traktat des Jehan Hérard zu den Herolden; eine Beschreibung der Art und Weise, wie Herolde zu ernennen sind; den Schwur, den sie ablegen müssen, und die Privilegien, die ihnen zustehen.

- Das dritte Buch beschreibt, wie, durch wen und wofür Tjosten, Turniere und appertises d'armes erstmals eingeführt wurden; wie sie in den alten Zeiten (anciennement) durchgeführt wurden; wie sie heute (à présent) durchzuführen sind; die Ordonnanz zu den gages de bataille und verschiedene, diese betreffende Regeln aus dem »Arbre des batailles«.

- Das letzte und vierte Buch schließlich gibt mehrere Einführungen zur Erlernung des Blasonierens von Wappen und den darin enthaltenen Farben sowie deren Bedeutung, mitsamt den Wappen mehrerer Könige, Herzöge, Fürsten, Grafen, Barone, Herren, Länder und Städte; die Kaiser und Päpste und die Abstammung der Jungfrau Maria; eine mit Wappen versehene Genealogie der Könige von Frankreich in Form eines Stammbaumes und der Fürsten und Herren, die von dieser Linie abstammen bzw. ihr durch Heirat verbunden sind.

Das erste Buch betrifft die Geschichte des Heroldsamtes, das zweite mehr oder minder dessen Gegenwart, das dritte ritterliche Zeremonien (wobei ebenso deren Geschichte wie Gegenwart beschrieben wird) und das vierte die für die Ausübung des Amtes notwendigen Fertigkeiten in der Wappenblasonierung sowie die Welt des Adels und dessen Symbole allgemein, hier vorwiegend in Wappensammlungen und Genealogien vermittelt. Faßt man dies noch einmal ganz allgemein zusammen, so geht es in der vorliegenden Kompilation um das Heroldsamt und den Adel.

Was nun den Gebrauch dieser Textsammlung angeht, so findet sich auch dafür ein kleiner Verweis in Siciles Prolog, wenn er schreibt, er habe die verschiedenen Texte angeordnet:

comme peult apparoir par la table qui s'ensieult, laquelle démonstre et enseigne les parties et chappitres dessus dicts, par le moyen du nombre adjousté à ladicte table, adfin de trouver plus légièrement les parties ou chappitres qu'on désire le plus à veoir et sçavoir, sans vacquer trop longuement à lire et veoir tout ledit livre qui ne veult ${ }^{27}$.

Im 15. Jahrhundert an sich schon längst bekannt, wird hier dennoch noch einmal die Intention des beigefügten Inhaltsverzeichnisses verdeutlicht und damit zugleich eine Gebrauchsanleitung für die vorliegende Kompilation geliefert. Denn diese sei so angelegt, daß der Leser leicht jene Stellen finden kann, die ihn direkt interessieren, ohne daß er hierfür das ganze Buch lesen bzw. durchsuchen müsse. Interessant dabei ist auch die Wortwahl. Es ist von »sehen « (à veoir) und »lesen«

27 Ibid., S. $1 \mathrm{f}$. 
(à lire) die Rede, nicht aber von »laut lesen« oder »lesen hören«. Der Text hebt damit eindeutig darauf $\mathrm{ab}$, daß ein einzelner Leser das Kompendium zur Hand nimmt und eigenständig heraussucht und liest, was ihn interessiert, wie es der Verwendung eines Handbuchs entspricht.

Faßt man damit die Beschreibung des »Kompendiums des Herolds Sicile« als potentielles Muster der Heroldskompendien zusammen, so läßt sich sagen, daß deren Inhalte sich sowohl mit dem Heroldswesen als auch mit dem Adel bzw. der adeligen Lebenswelt als solcher auseinandersetzen sollten. Hinsichtlich des Heroldswesens können dabei Traktate zu dessen Geschichte, Organisation und Gegenwart unterschieden werden, die jedoch stets eng ineinander übergreifen. Historische Grundlagen dienen zumeist der Erklärung der Gegenwart, während die Gegenwart zumeist durch die Geschichte begründet wird. Eine klarere Differenzierung hingegen erlauben die Texte zum Adelswesen, indem hier zwischen Informationen zu den Zeremonien der adeligen Gesellschaft und den speziellen Fähigkeiten sowie allgemeinen Wissensgrundlagen für die Auseinandersetzung mit deren Repräsentation und Organisation unterschieden werden kann. Die Texte wurden dabei mit der Intention zusammengestellt, einen gewissen Wissensstandard und ein bestimmtes Verständnis des Amtes der Herolde zu propagieren.

\subsection{Siciles Kompendium im Kontext der Überlieferung}

\subsubsection{Ausnahme in Text und Form}

Überblickt man daraufhin den für das 15. Jahrhundert zusammengetragenen Bestand an potentiellen Heroldskompendien, so ist als erstes festzustellen, daß der integrale Text des »Kompendiums des Herolds Sicile« für diesen Zeitraum allein in der genannten Pariser Handschrift überliefert ist. Ansonsten gibt es nur in der Biblioteca Apostolica Vaticana ein weiteres Manuskript, welches auch mehrere zusammenhängende Teile des Kompendiums von Sicile überliefert ${ }^{28}$. Doch ist dessen Struktur hier aufgelöst, sind die Texte nur zum Teil enthalten, umgestellt und mit anderen Traktaten vermengt. Der Prolog fehlt ganz. Auch für die spätere Zeit konnten bisher nur drei Überlieferungen gefunden werden, von denen zwei ebenfalls erhebliche Veränderungen erfahren haben. Dabei handelt es sich mit aller Wahrscheinlichkeit um Bearbeitungen durch Roland Bournel (†1537), Seigneur von Boncourt, Mamez etc. ${ }^{29}$, der ebenso Eingriffe in den Text wie in dessen Anordnung vornahm, einige Traktate neu dazwischenschob, andere dafür entfernte. Der Kolophon eines der Texte in der Londoner Kopie verweist auf das Jahr $1540^{30}$. Eine spätere Pariser Handschrift stammt aus dem 17. Jahrhundert ${ }^{31}$.

28 Vgl. Vatikan, BAV, Ottoboni lat. 2257.

29 Vgl. ANSELME, Histoire généalogique, Bd. VIII, S. 154.

30 Vgl. London, BL, Royal 20 B XVI, fol. 75r.

31 Vgl. Paris, BnF, fr. 31842. 


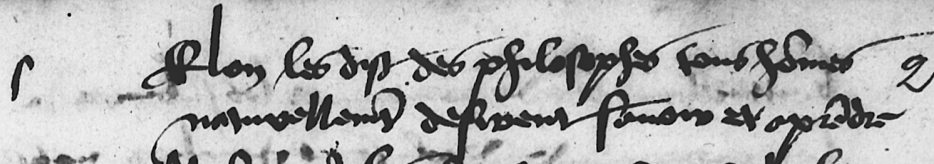

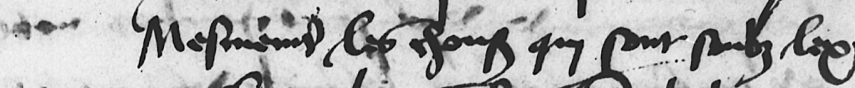

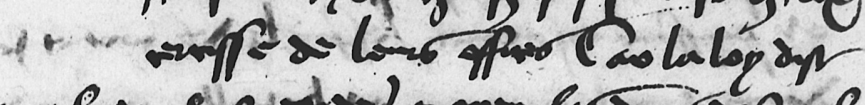

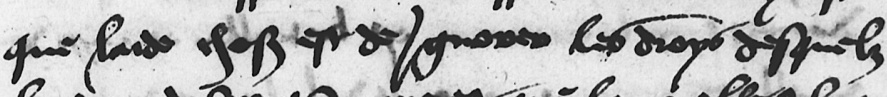

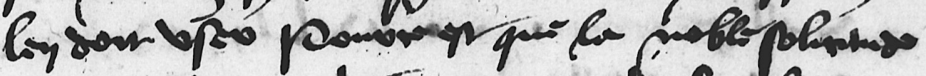

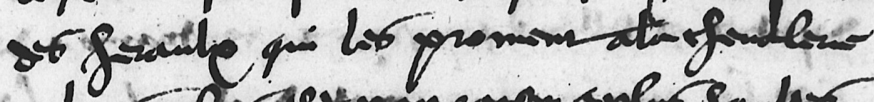

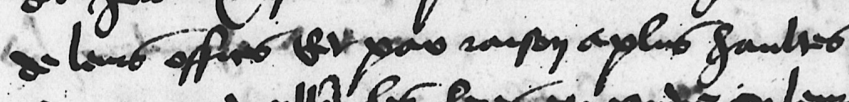

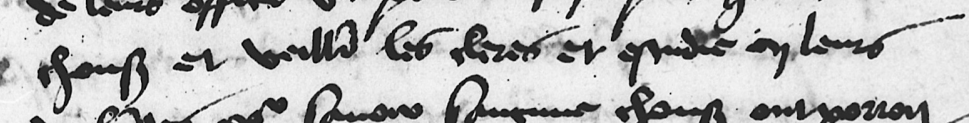

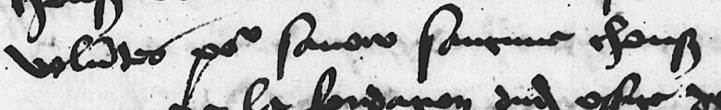

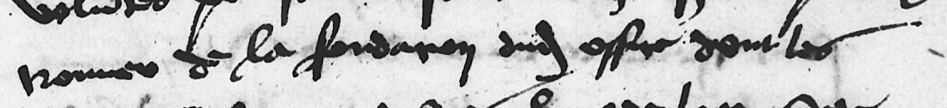

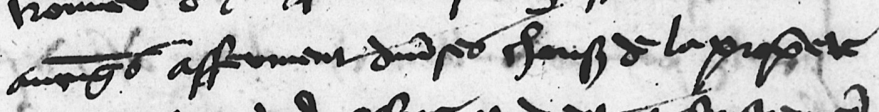

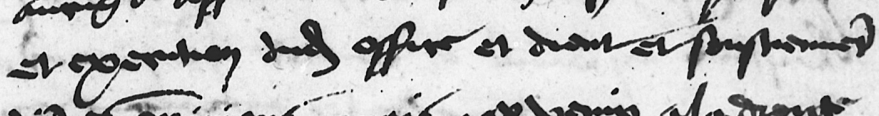

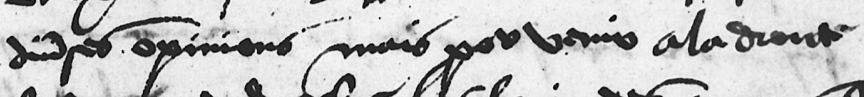

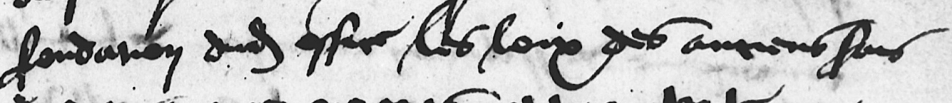

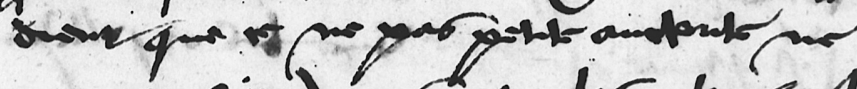

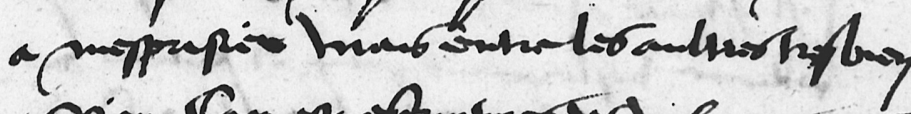

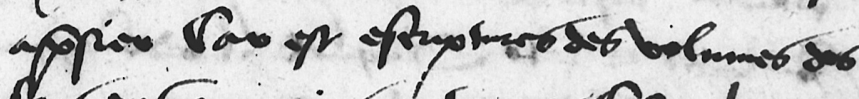

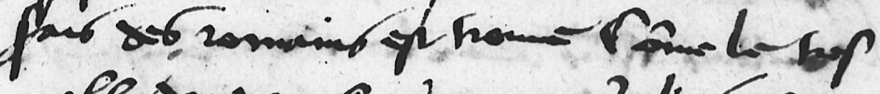

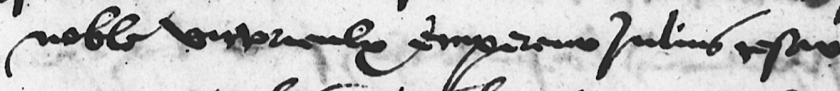

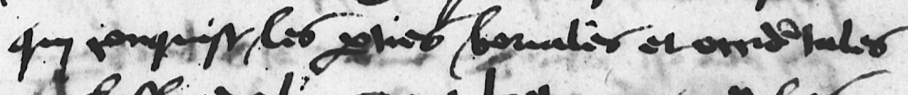

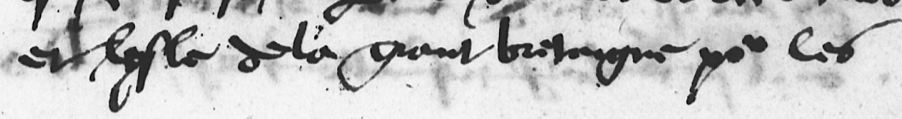




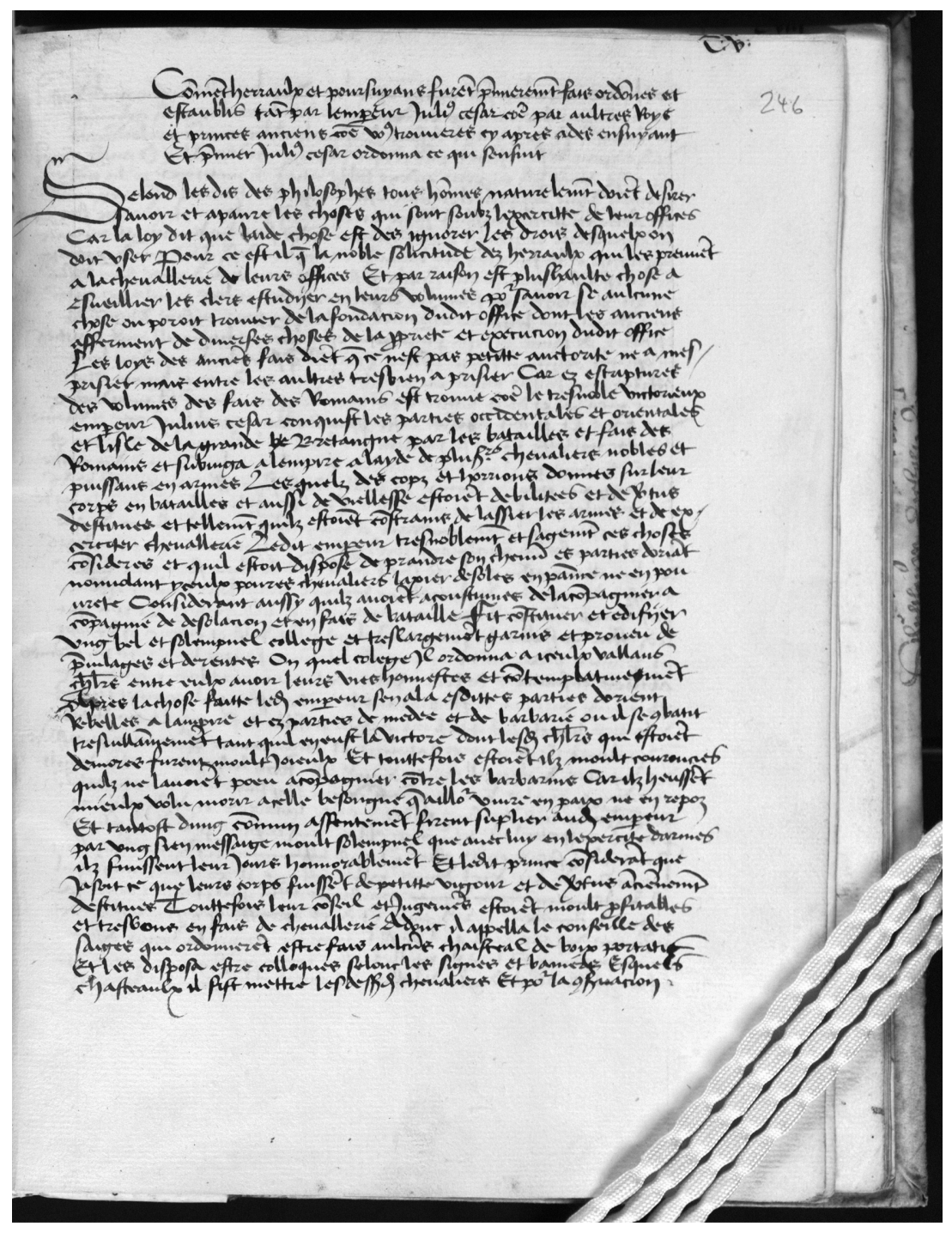

Abb. 2: Erste Seite des »Metzer Kompendiums" in der Handschrift Bern, Burgerbibliothek, A 280 (»Selon les ditz-Traktat«, fol. CVr) 


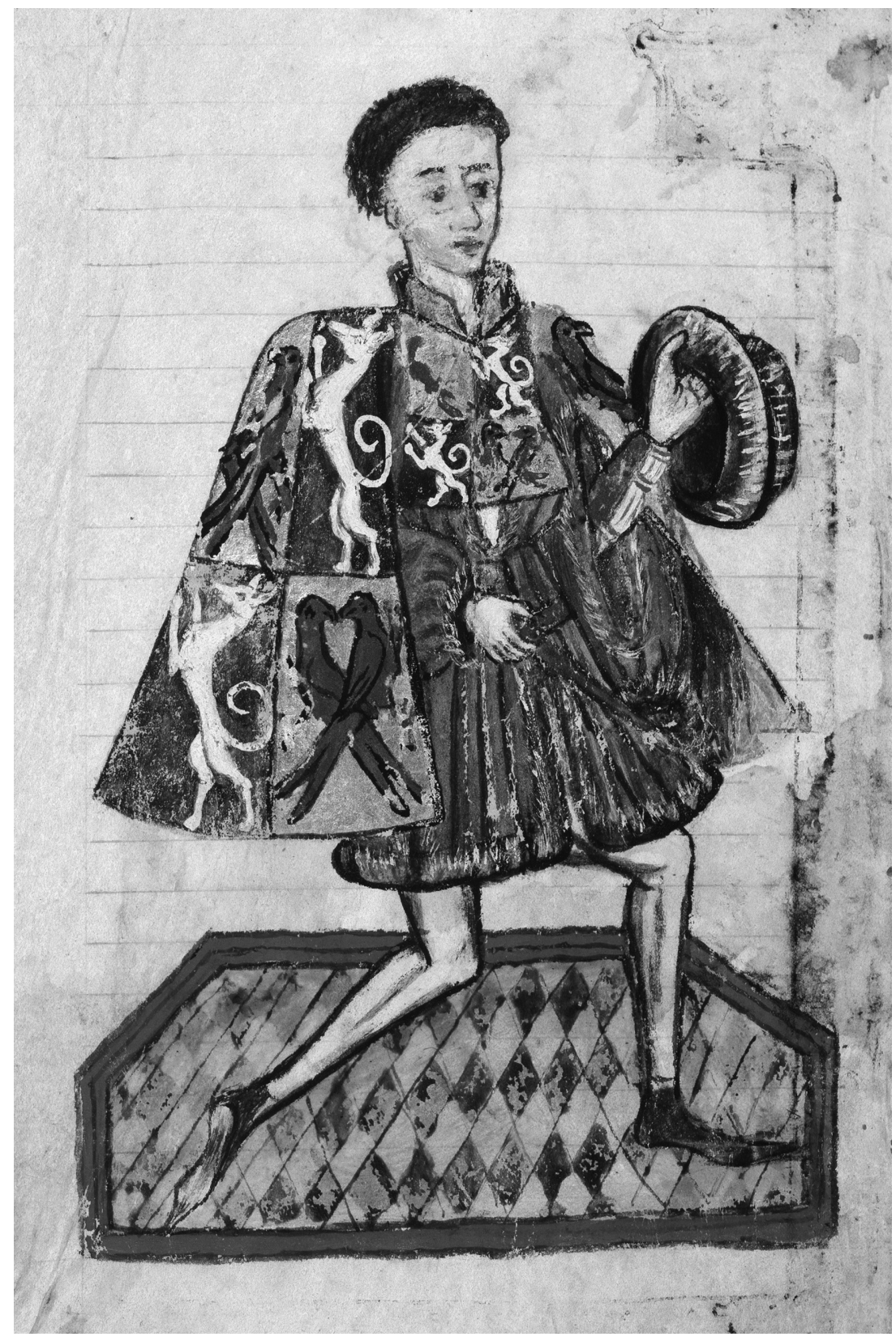

Abb. 3: Unbekannter Persevant. Eröffnungsminiatur der Handschrift Wien, ÖNB, 2652, fol. $1 v$ 


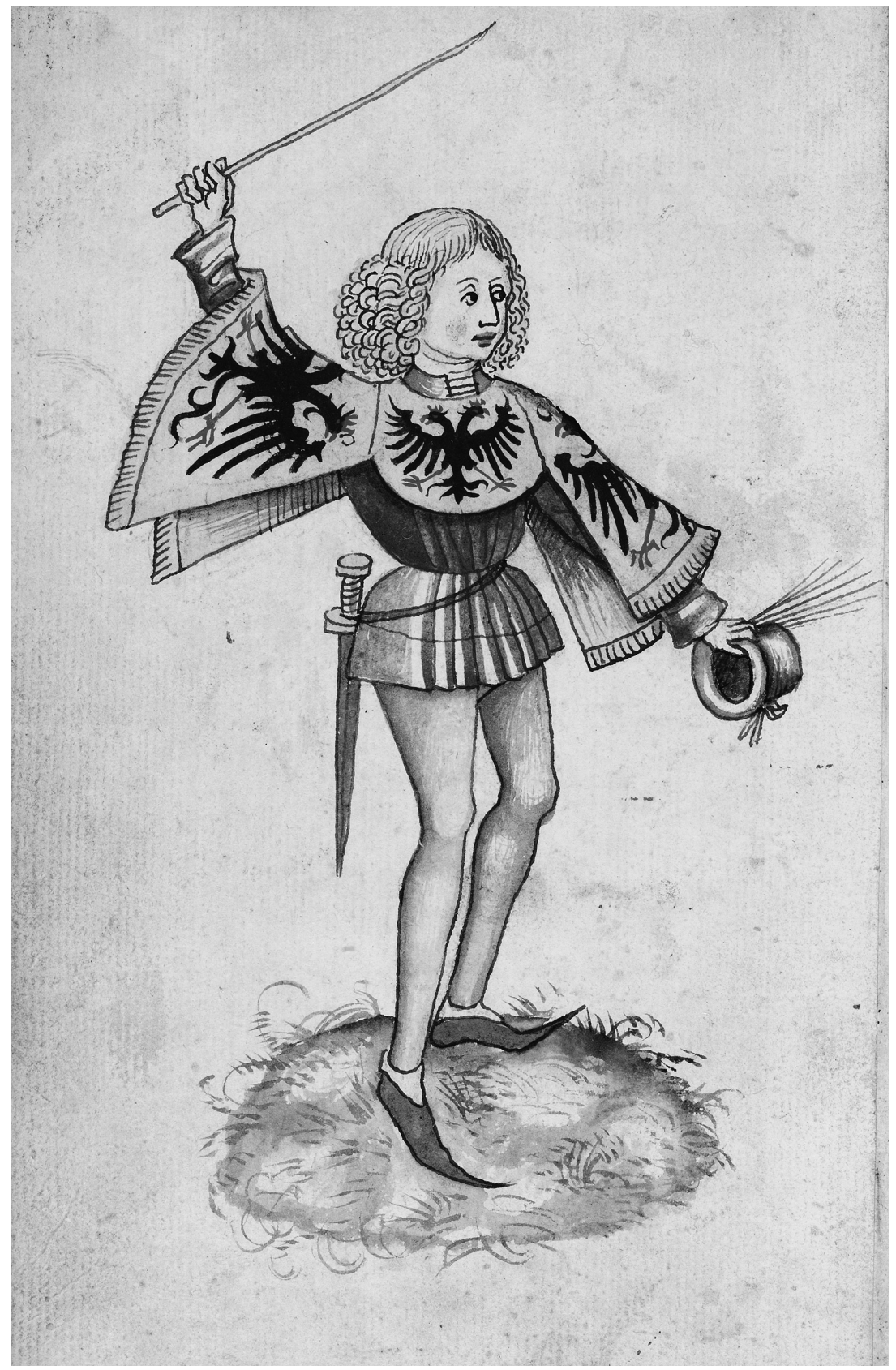

Abb. 4: Persevant im Wappenrock des römischen Kaisers bzw. des Julius Cäsar. Eröffnungsminiatur der Handschrift Oxford, Bodl. Lib., Douce 278, fol. IIv 


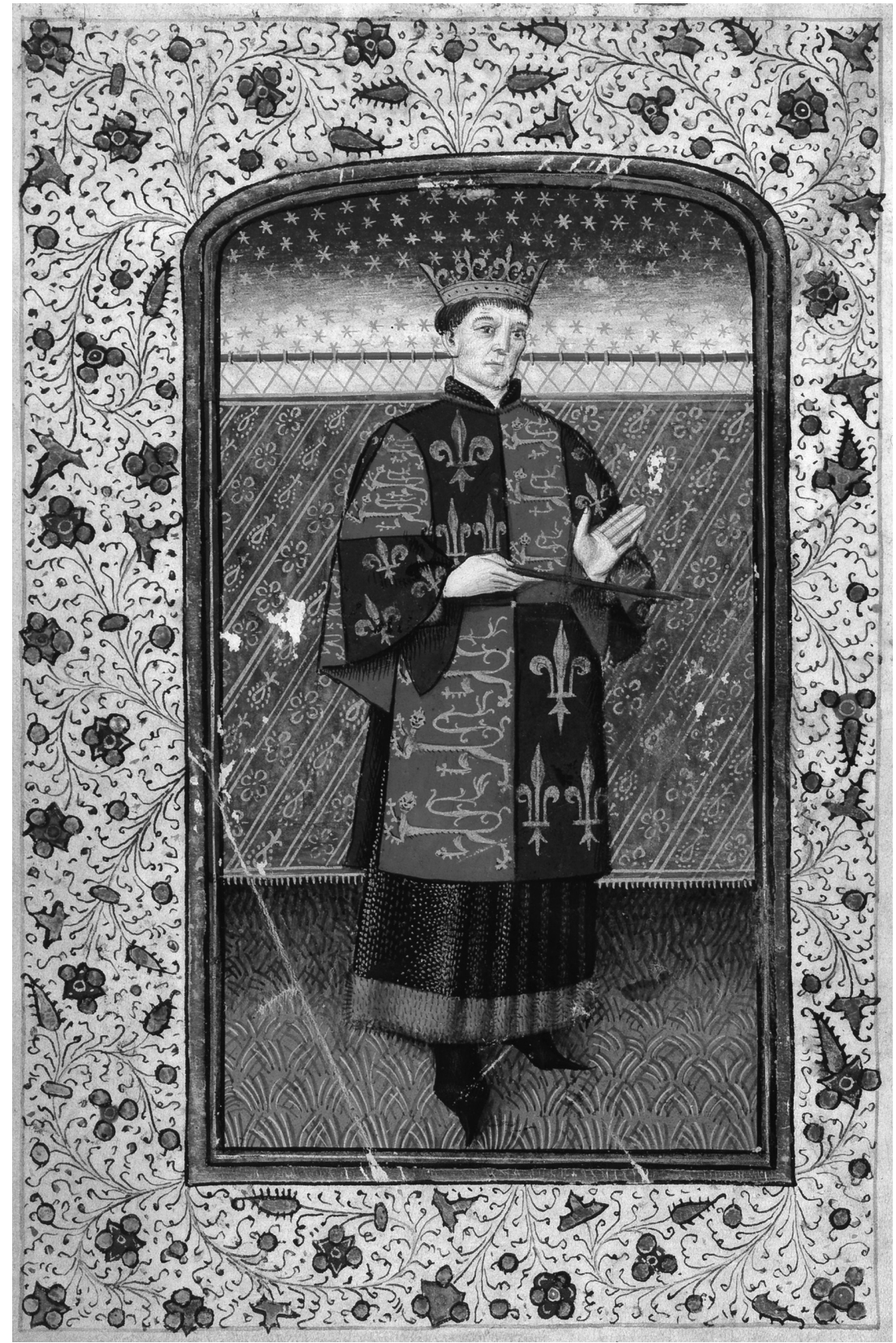

Abb. 5: Englischer Wappenkönig. Eröffnungsminiatur der Handschrift Oxford, Bodl. Lib., Ashmole 764, fol. IVv 


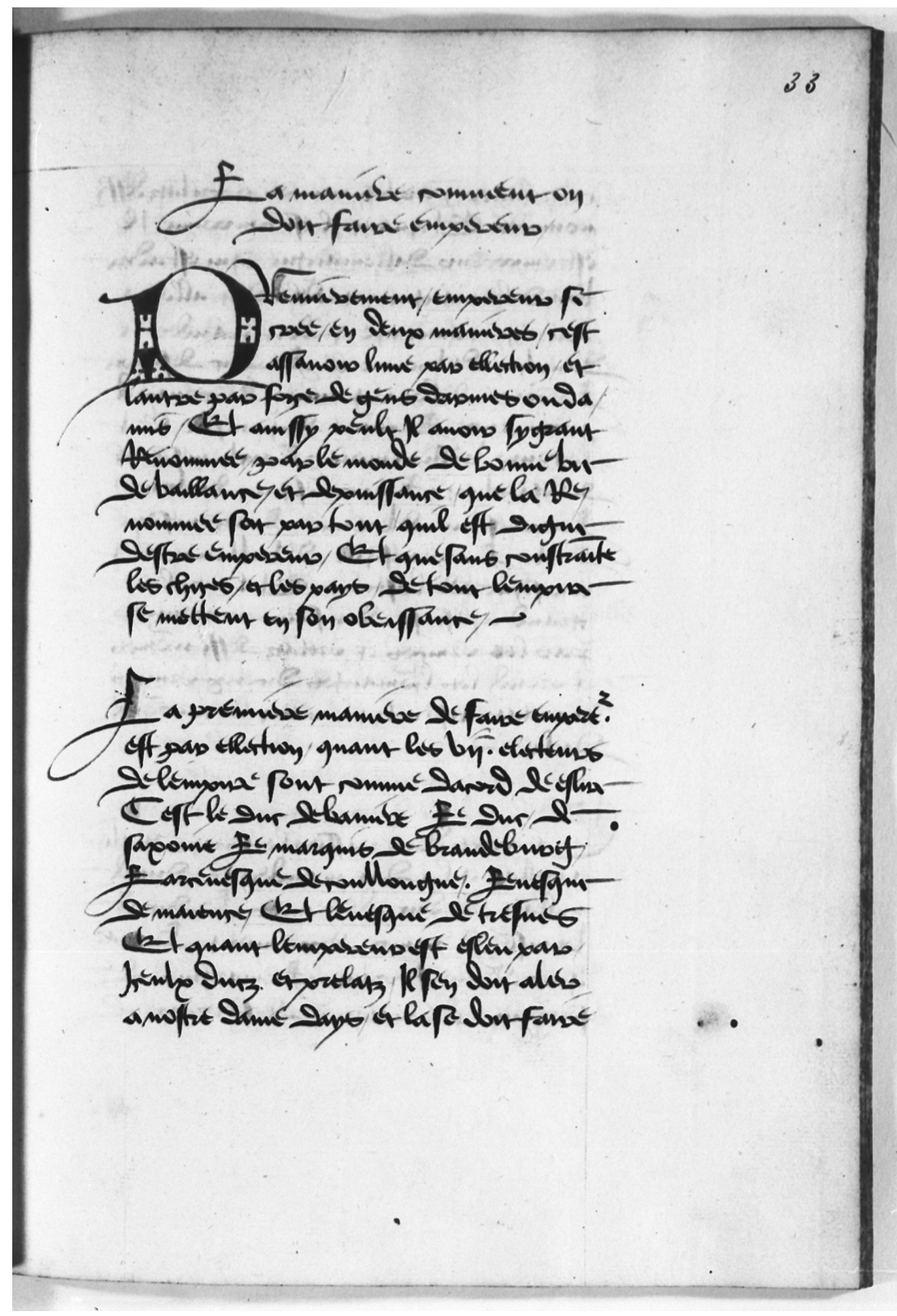

Abb. 6: Seite aus der Handschrift Paris, BnF, fr. 23998 (Beginn des »Empereur-Traktates«, fol. 33r) 


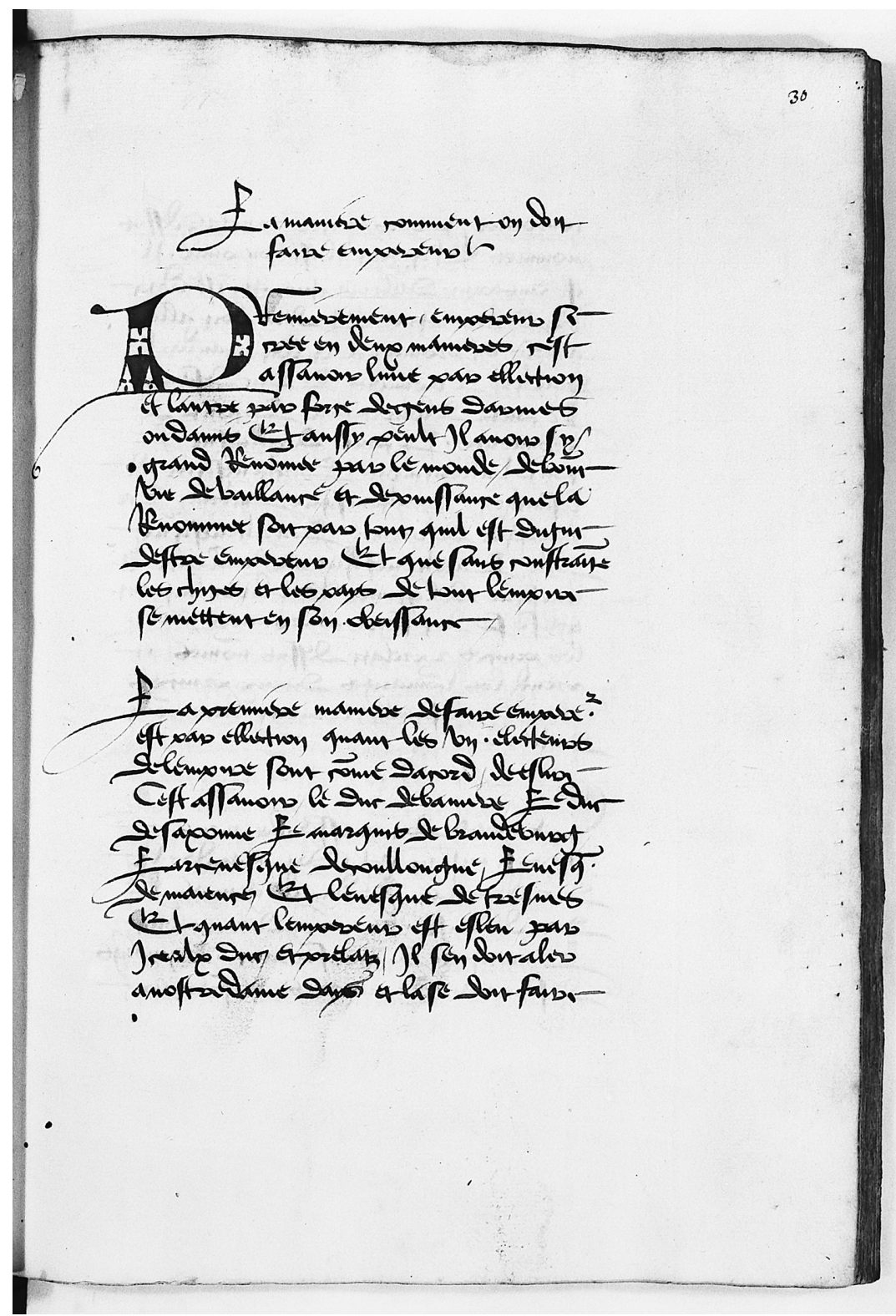

Abb. 7: Seite aus der Handschrift Paris, Arsenal, 4655 (Beginn des »Empereur-Traktates«, fol. 30r) 


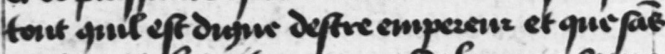

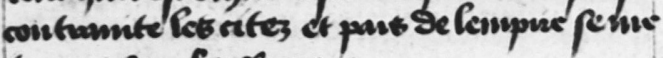
tent ea) pon obeypance.

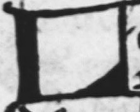

apremene de farre emporesur of

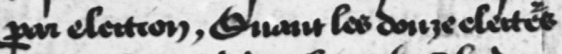

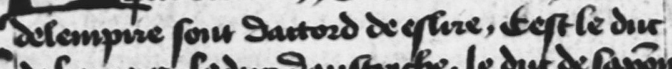

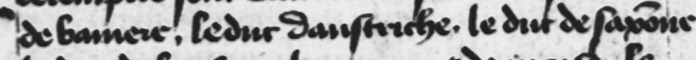

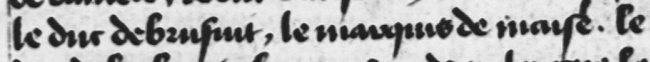

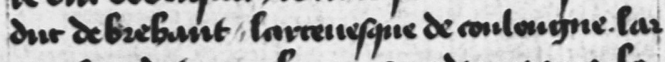

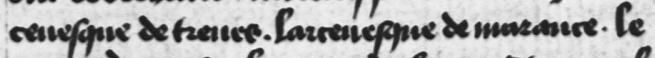

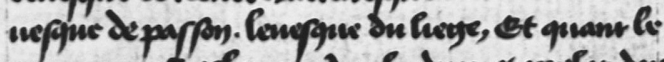

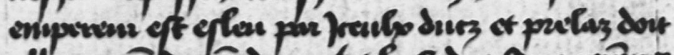

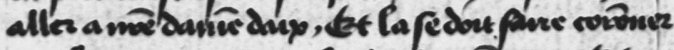

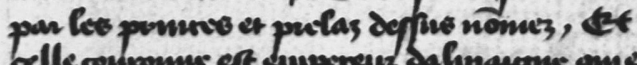

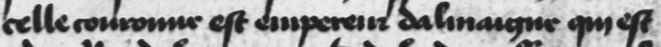

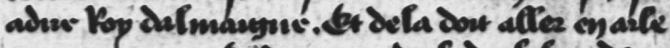

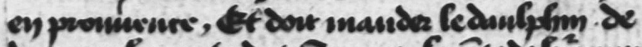

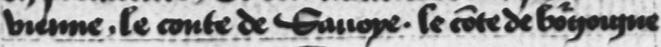

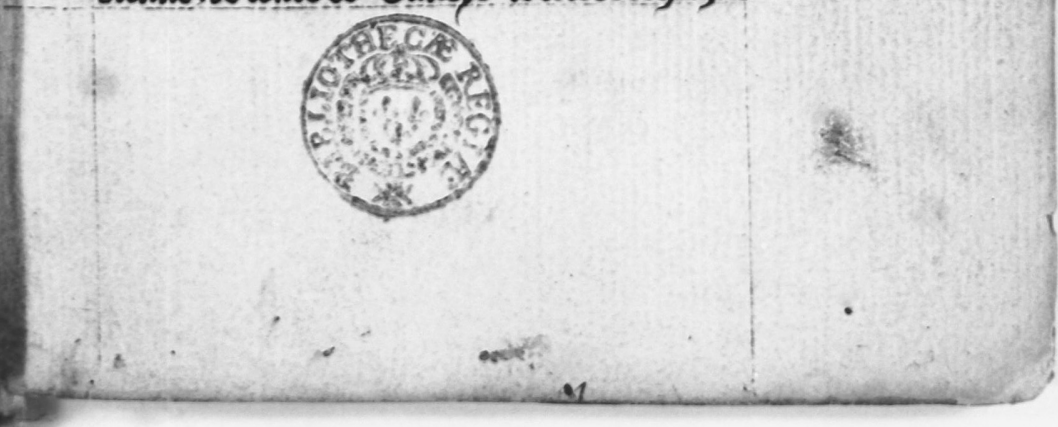

Abb. 8: Erste Seite der Handschrift Paris, BnF, fr. 1983 (»Angevinisches Heroldskompendium «, fol. 3r, Mitte 15. Jh.) 


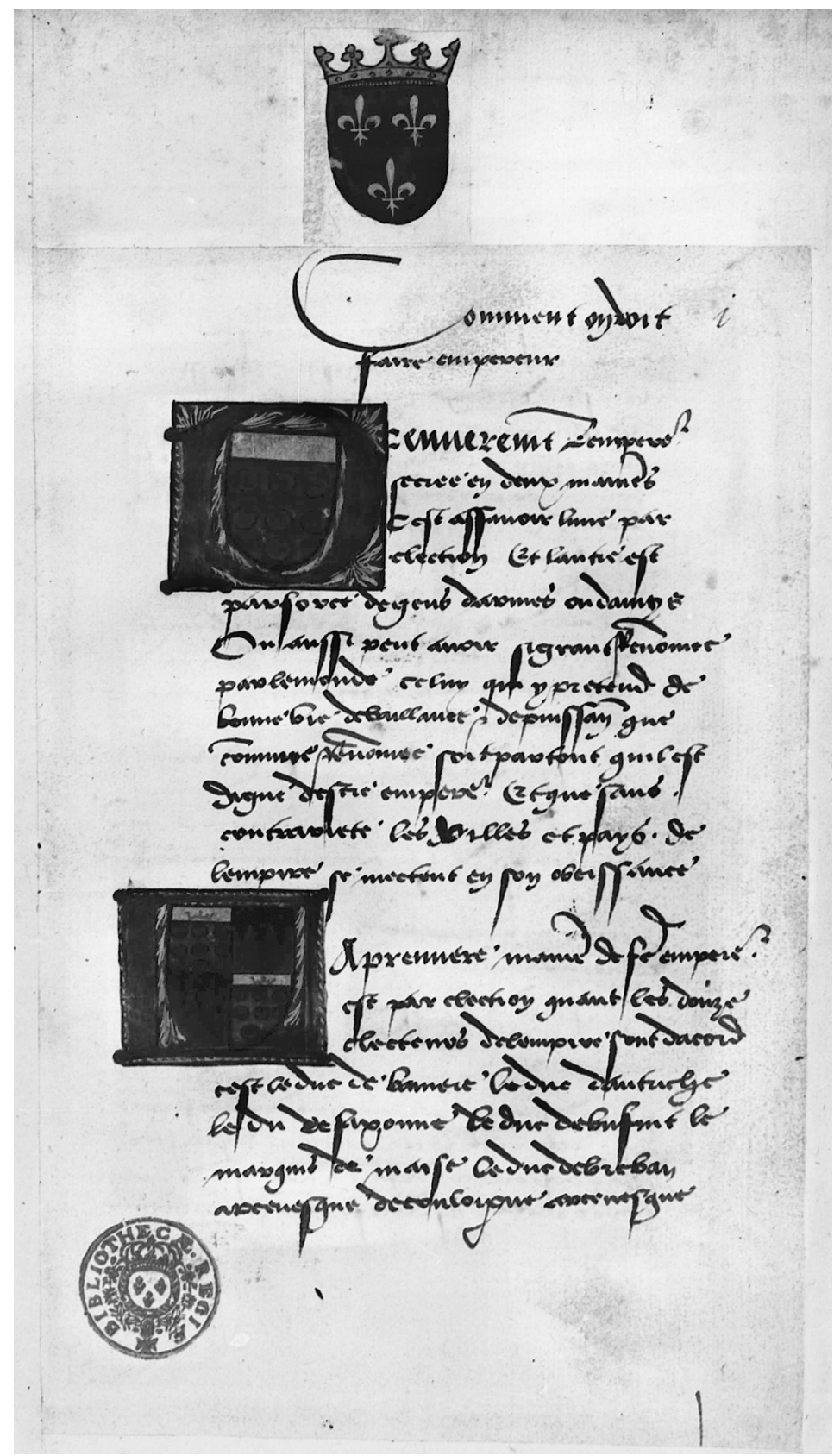

Abb. 9: $\quad$ Erste Seite der Handschrift Paris, BnF, fr. 5241 (»Angevinisches Heroldskompendium«, fol. $1 r$, um 1500) 


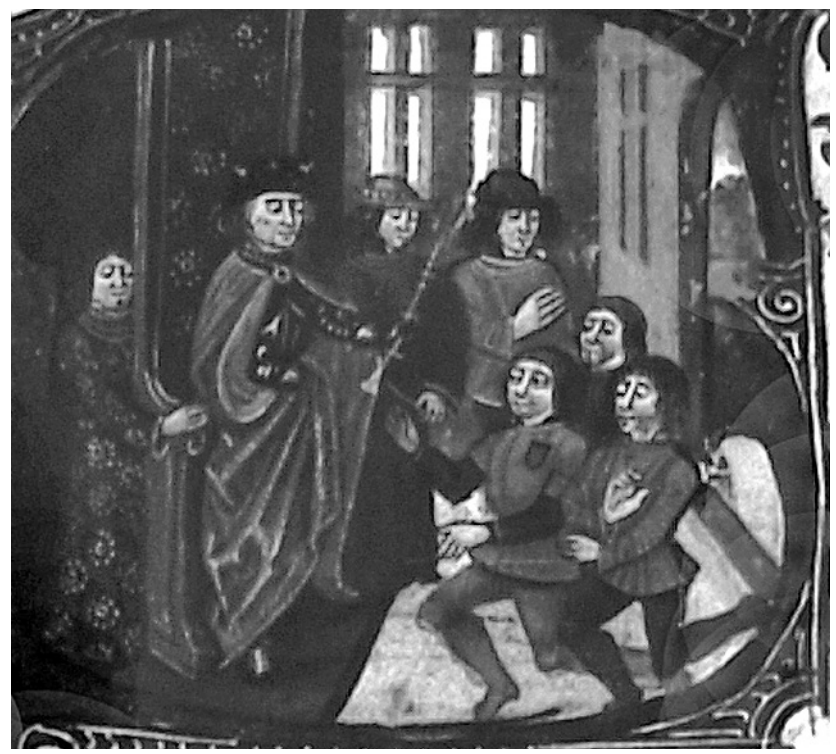

Abb. 10: Ernennung eines neuen Herolds. Historisierte Initiale am Beginn des »Zwischenprologes des Kompendiums Ludwigs von Brügge" (Paris, BnF, fr. 1280, fol. 112v)

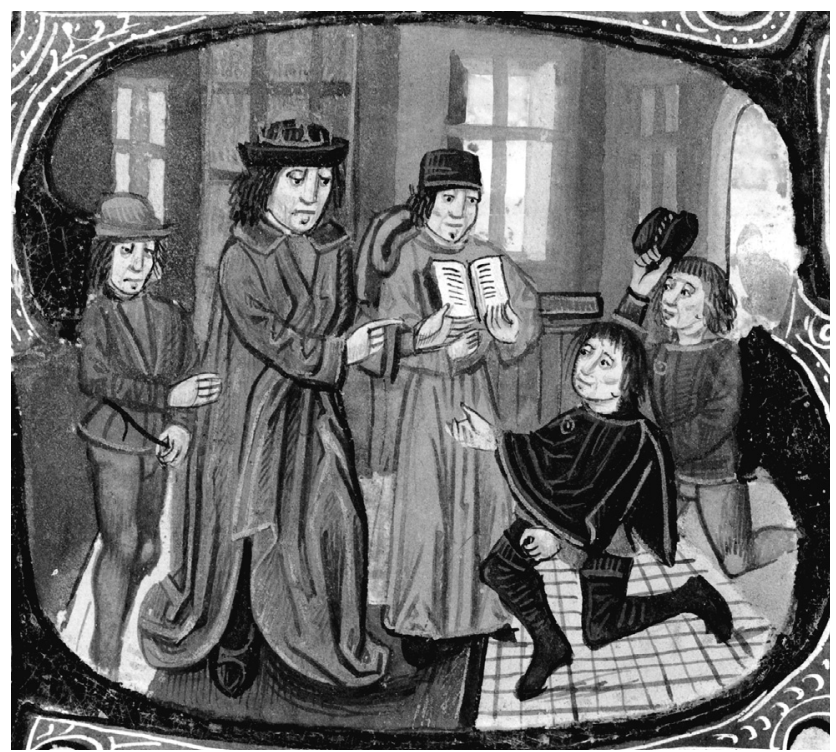

Abb. 11: Ernennung eines neuen Herolds. Historisierte Initiale am Beginn des »Zwischenprologes des Kompendiums Ludwigs von Brügge« (Wien, ÖNB, 2616, fol. 113v) 


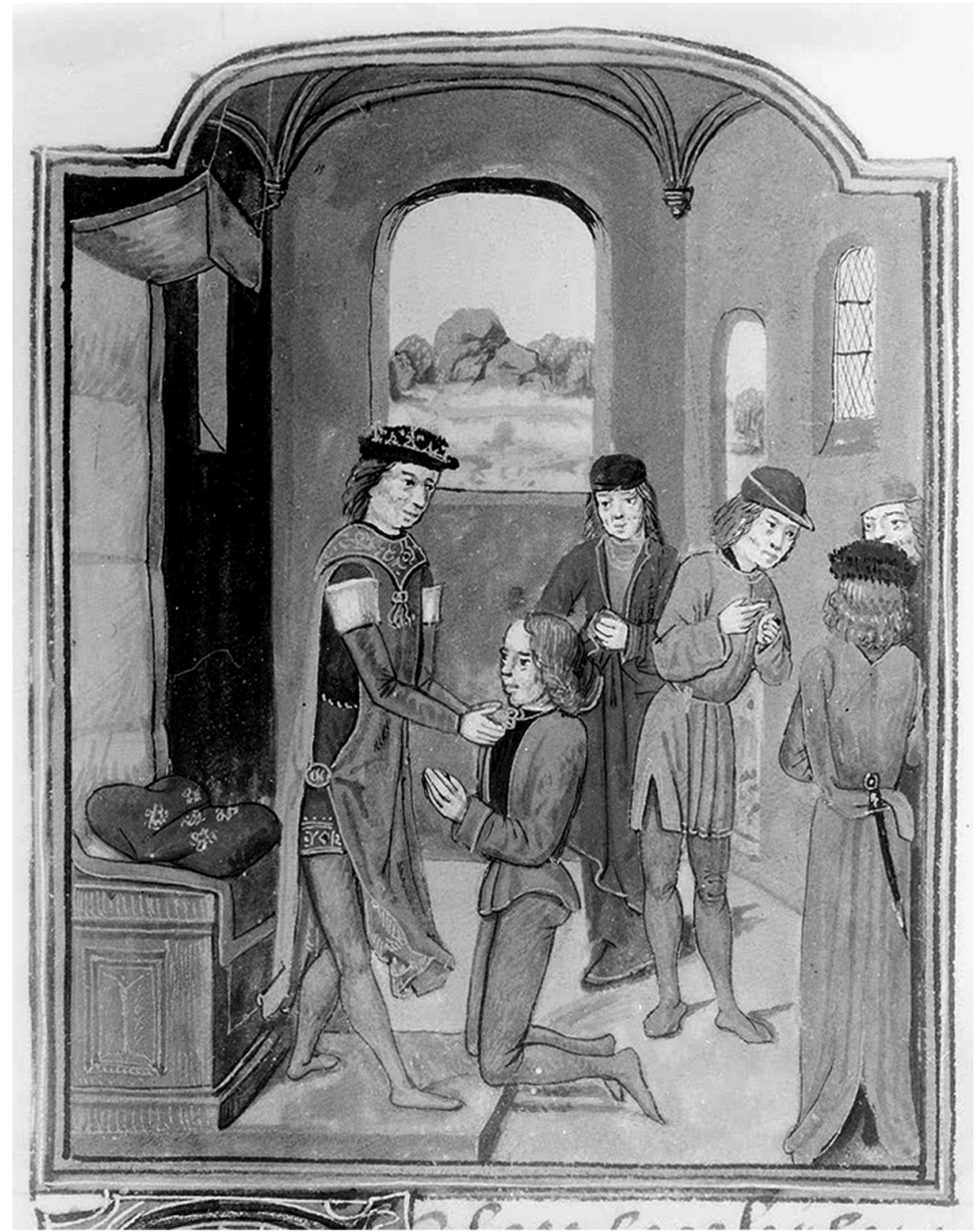

Abb. 12: Ernennung eines neuen Herolds. Kolumnenbild am Beginn des »Zwischenprologes des Kompendiums Ludwigs von Brügge" (New Haven, Yale University Library, Beinecke ms. 230, fol. 179r) 


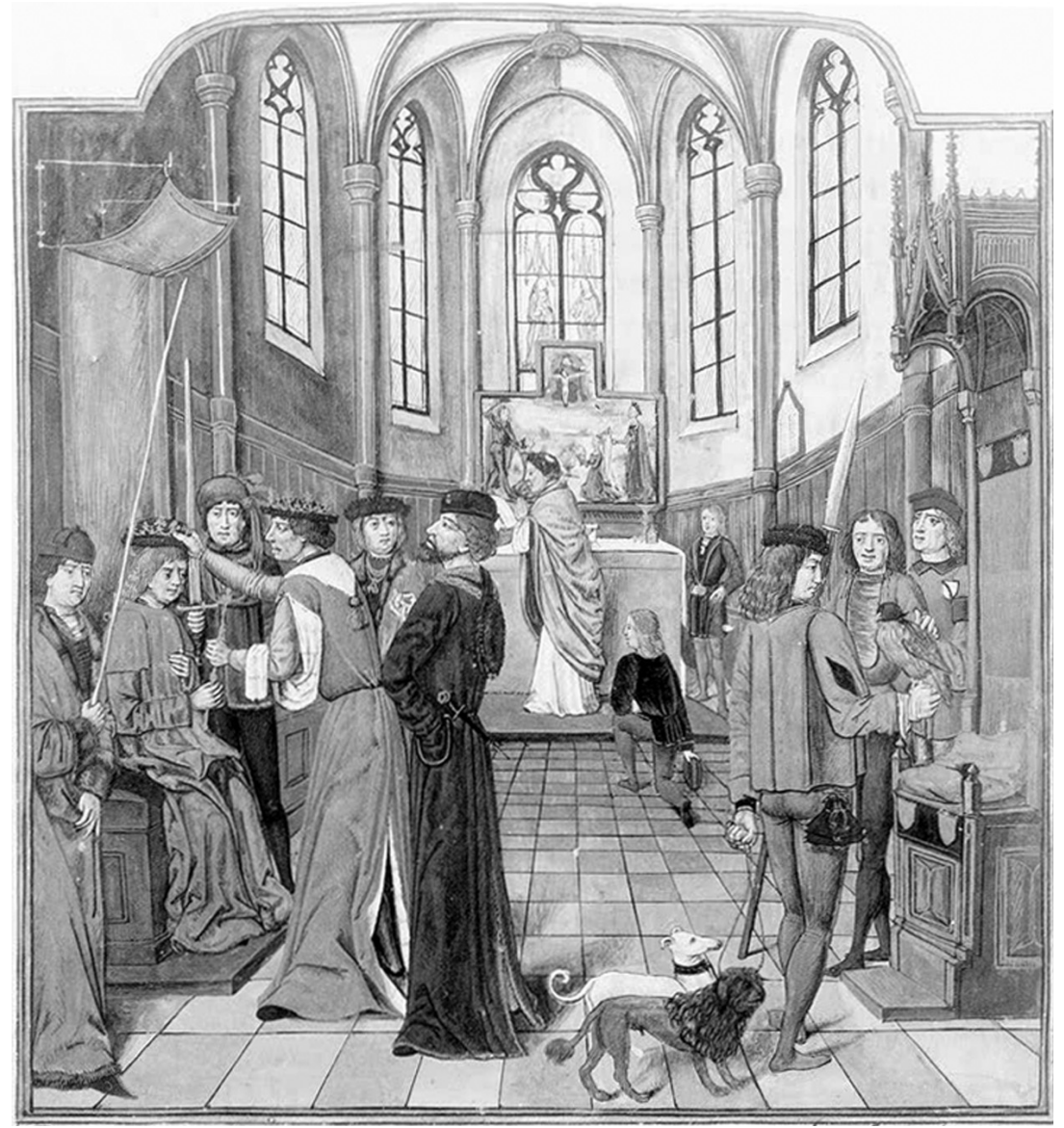

Abb. 13: Krönung des obersten französischen Wappenkönigs Montjoye. Eröffnungsminiatur zum "Montjoye-Traktat" (New Haven, Yale University Library, Beinecke ms. 230, fol. 198r) 


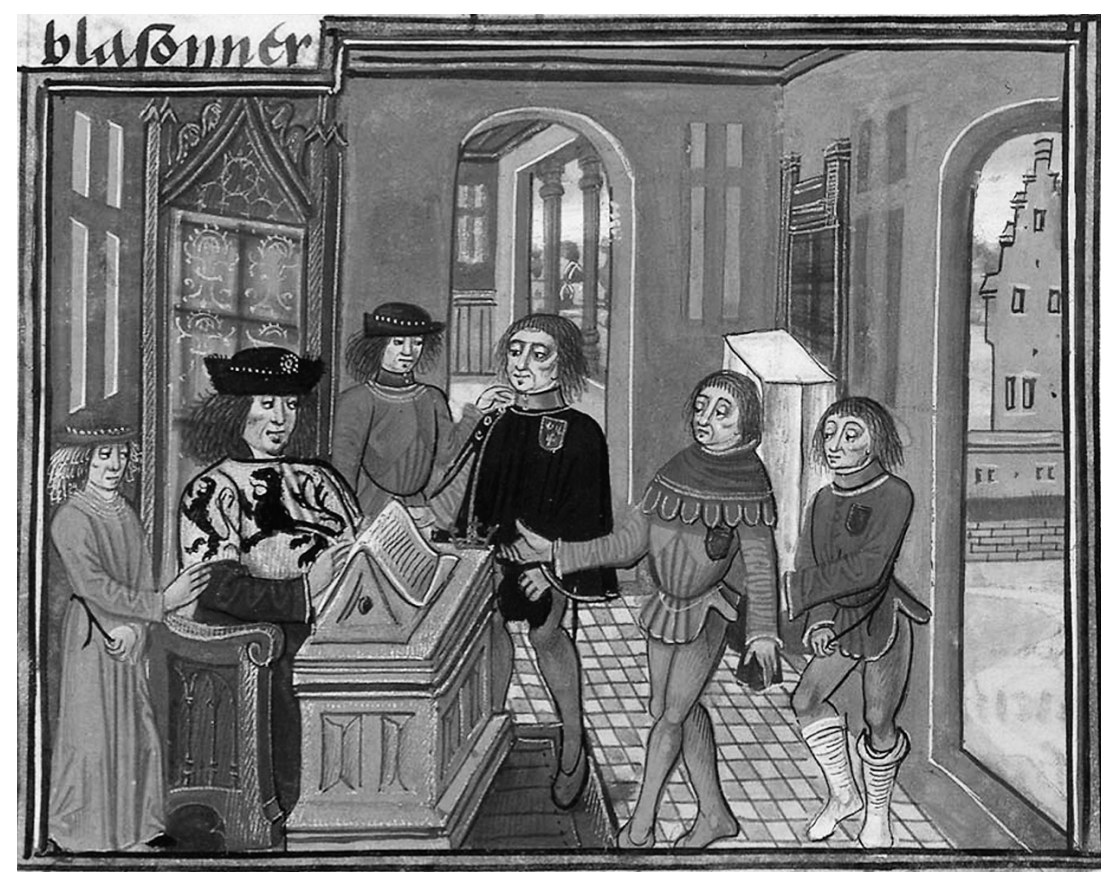

Abb. 14: Autorenbild am Beginn des »Prinsault-Traktates« (Paris, BnF, fr. 1280, fol. 59r)

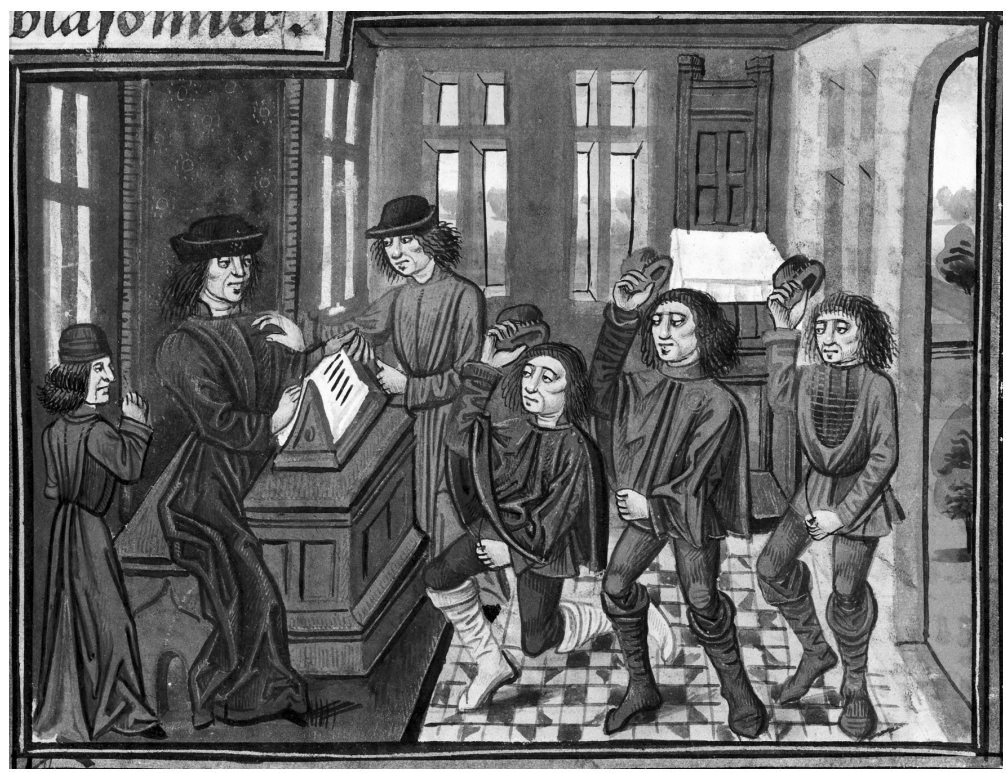

Abb. 15: Autorenbild am Beginn des »Prinsault-Traktates« (Wien, ÖNB, 2616, fol. 60r) 


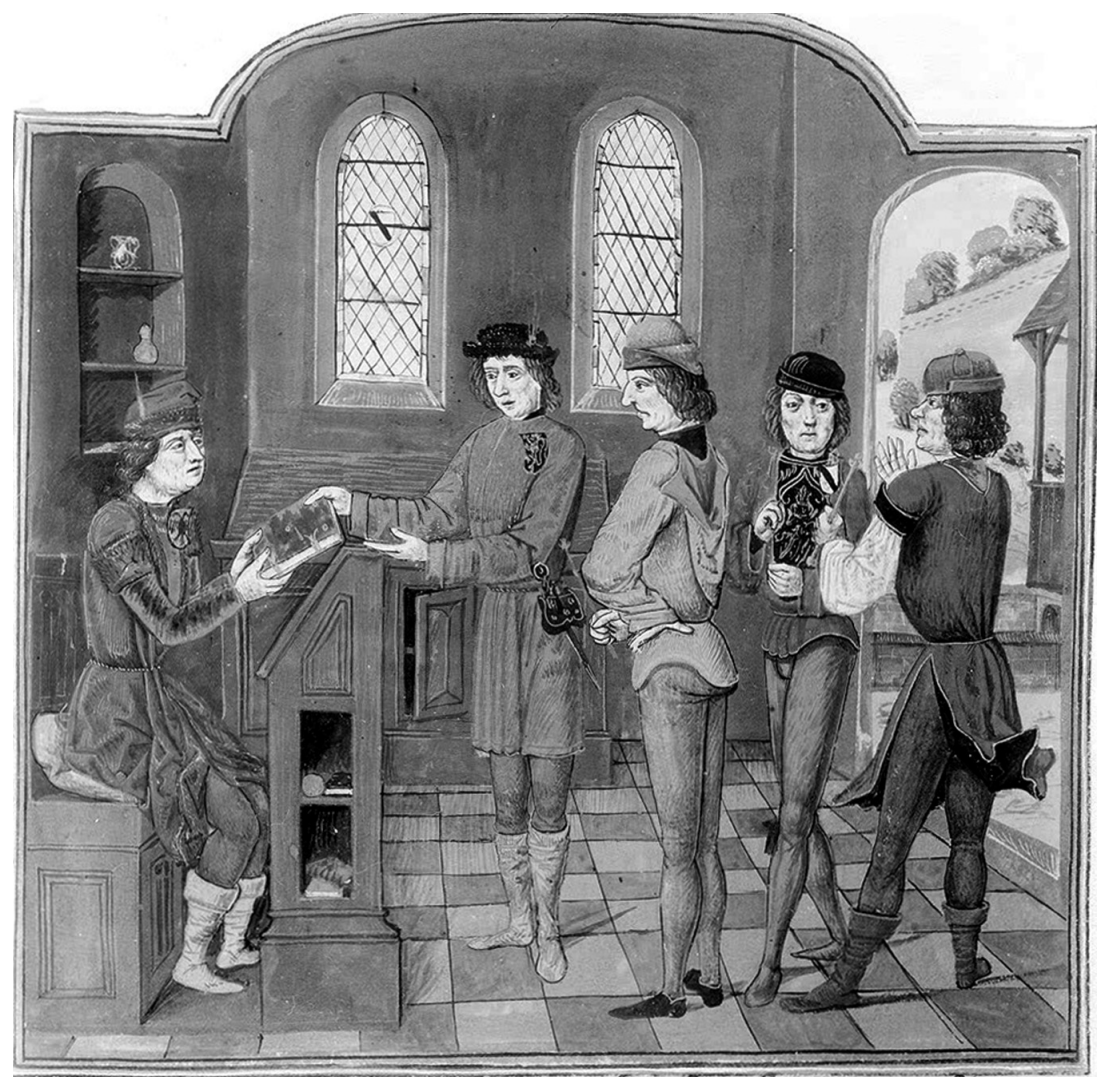

Abb. 16: Autorenbild am Beginn des »Prinsault-Traktates« (New Haven, Yale University Library, Beinecke ms. 230, fol. 145r) 


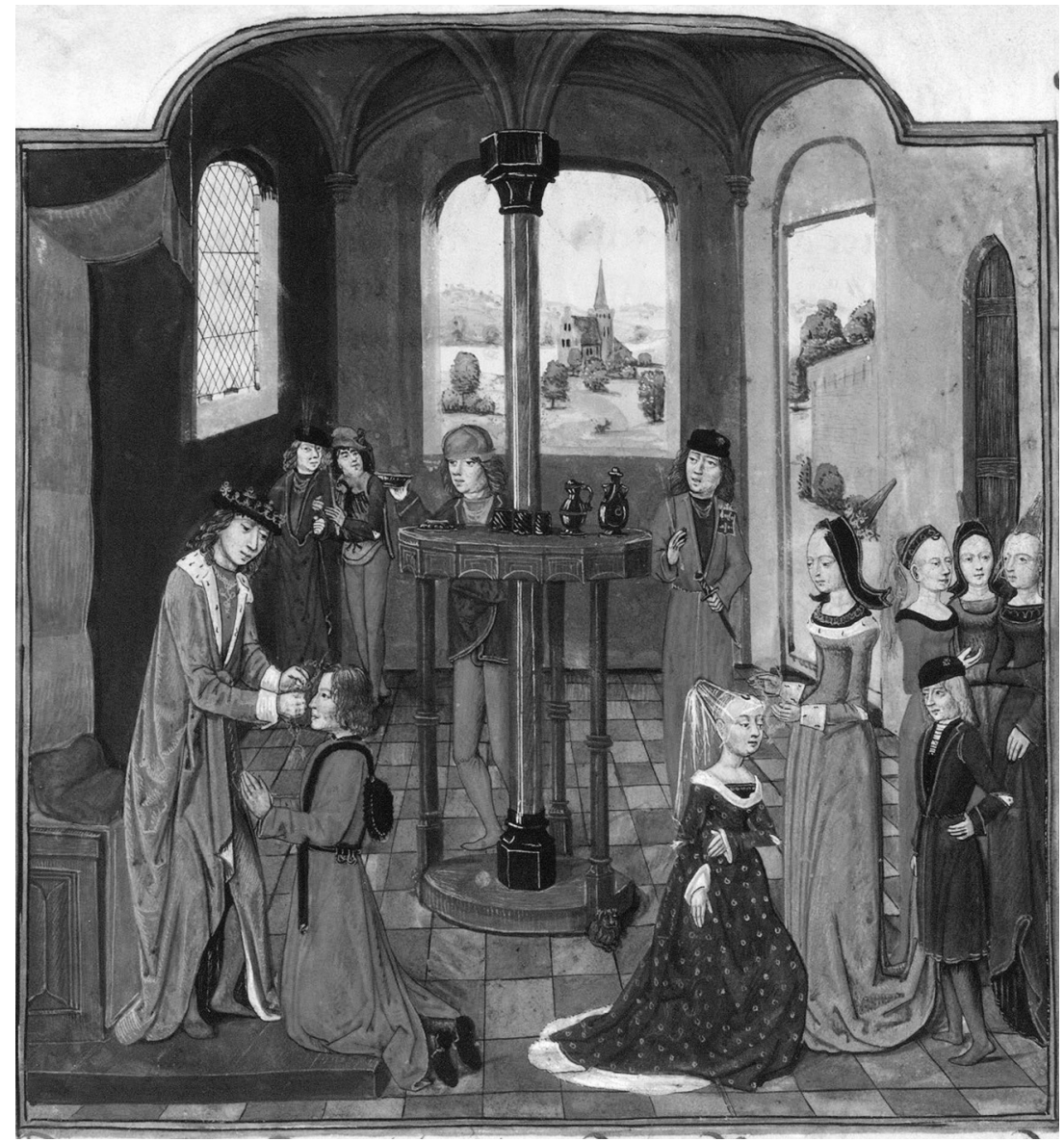

Abb. 17: Verleihung des Ordens vom Goldenen Vlies durch Maximilian von Österreich? Miniatur am Beginn des »Adelstraktates des Diego de Valera" (New Haven, Yale University Library, Beinecke ms. 230, fol. 118r) 


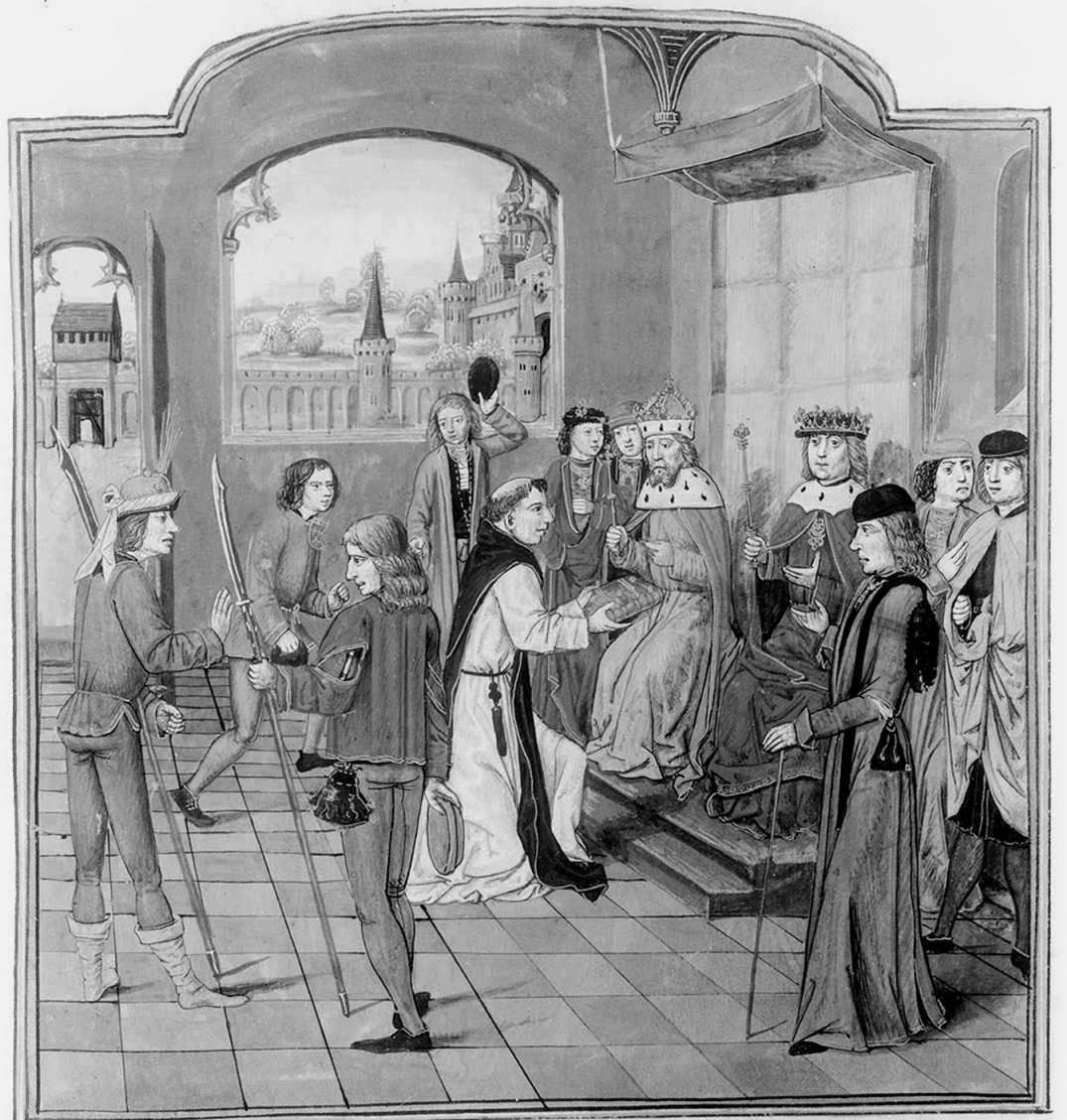

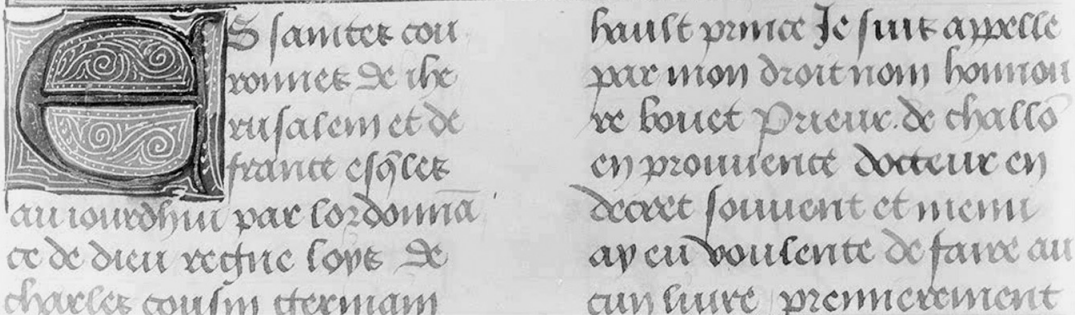

Abb. 18: Dedikationsbild am Beginn des »Arbre des batailles" von Honoré Bouvet (New Haven, Yale University Library, Beinecke ms. 230, fol. 10r) 
Integral ist der Text der Kompilation des Herolds Sicile nur einmal noch überliefert, in einer Handschrift aus dem 16. Jahrhundert in der British Library in London ${ }^{32}$. Wie aber der Textabbruch am Ende der Handschrift und die darin enthaltenen Miniaturen belegen, steht diese in einem direkten Abhängigkeitsverhältnis zu der Pariser Handschrift BnF, fr. 387, der Vorlage für die Edition Père Rolands.

Dies bedeutet, daß einige jener Traktate, denen aufgrund ihrer Überlieferung in dem als Edition zugänglichen »Kompendium des Herolds Sicile « bisher recht große Bedeutung zugemessen wurde, für das 15. Jahrhundert nur ein einziges Mal überliefert sind. Dazu zählen vor allem - und dies ist erstaunlich - die Gründungsakten und Statuten der französischen Heroldsvereinigung von 1407. Aber auch Siciles Darstellungen »Zur Vorgeschichte des Heroldsamtes«, welche die Kompilation eröffnen, sowie der hier enthaltene Rittertraktat sind davon betroffen.

Nicht nur inhaltlich, auch formal stellt die Pariser Handschrift des Sicile-Kompendiums - eine Papierhandschrift mit Miniaturen in Wasserfarben, groß dimensioniert (ca. $400 \times 280 \mathrm{~mm}$ ) und zweispaltig angelegt - eine Ausnahme dar. Alle weiteren Überlieferungen lassen sich nur entweder einer sehr umfangreichen Gruppe von Privatkopien zuordnen, die viel bescheidener angelegt und ausgestattet waren als die vorliegende Kopie. Oder aber sie sind den bei weitem selteneren Prunkcodices zuzuzählen.

Besonders hervorzuheben ist jedoch der dem »Kompendium des Herolds $\mathrm{Si}$ cile« voranstehende Prolog, der in seiner ausführlichen und pointierten Weise einmalig ist. Nur zwei weitere, aus dem 15. Jahrhundert überlieferte Kompilationen verfügen noch über eine kurze Einführung durch den Kompilator bzw. auch über einen Epilog 33 . Bei der restlichen Überlieferung handelt es sich hingegen um kommentarlos aneinandergereihte Traktatsammlungen in immer wieder variierender Zusammensetzung, ohne jegliche Angabe zu Intention oder Inhalt.

Mit dem Prolog aufs engste verbunden ist die Selbstnennung des Kompilators, die im Falle Siciles in der Forschung teilweise auch als Autorenbezeichnung fehlverstanden wurde ${ }^{34}$. Abgesehen von dem »Kompendium des Herolds Sicile« ist nur eine einzige weitere Kompilation mit einem eigenen Verweis auf deren Kompilator versehen. Hier heißt es:

Car certes, je ne suis de leur office ne digne de l'estre, mais ce que j'en ay escript ça esté au commandement de mon bon filz, sage et prudent, Gilles ********, roy d'armes de Flandres soubz tresillustre et tresexcellent prince Maximilian, duc d'Ostrice, de Bourgogne, de Brabant ${ }^{35}$.

Diese Kompilation wurde demnach also nicht durch einen Herold verfaßt, sondern nur unter der Aufsicht eines solchen. Bei diesem, der in dem auf 1481 datier-

32 Vgl. London, BL, Add. 17351.

33 Vgl. Paris, BnF, fr. 1280 und fr. 11464.

34 Vgl. z. B. WaGner, Heralds of England, S. 40 und passim, sowie Dennys, The Heraldic Imagination.

35 Paris, BnF, fr. 1280, fol. 134r. Zu dem entsprechenden Heroldskompendium und den damit verbundenen Problemen siehe noch unten, Kap. 3.2.8. 
ten Text nur unvollständig als Gilles, roy d'armes de Flandre genannt wird, handelt es sich um Gilles Nokerscot, der zuvor Karl dem Kühnen als Persevant J'ay l'emprins und dann als Herold Fusil diente ${ }^{36}$. Der eigentliche Kompilator hingegen bleibt auch hier ungenannt ${ }^{37}$.

Unter formalen wie unter strukturellen Aspekten steht das »Kompendium des Herolds Sicile « von daher relativ allein. Dessen Rahmentexte und die darin unternommenen Adressierungen und festgehaltenen Intentionen sind in der weiteren Überlieferung ohne Parallelen. Anders verhält es sich aber unter inhaltlichen Gesichtspunkten.

\subsubsection{Exemplarisch in Thema und Inhalt}

Fahndet man innerhalb der aus dem 15. Jahrhundert ganz allgemein zusammengetragenen Textsammlungen nach Kompilationen, die sich wie die des Herolds Sicile sowohl mit dem Heroldswesen als auch mit der adeligen Lebenswelt auseinandersetzen, hebt sich jedoch eine Gruppe von Überlieferungen heraus, in der sich annähernd das gleiche Programm umgesetzt findet, wie es Herold Sicile in seinem Prolog skizzierte. Texte zur Geschichte und Gegenwart des Heroldswesens sind hier genauso versammelt wie Darstellungen zu adeligen Zeremonien, spezifischen Fertigkeiten und allgemeinen Wissensgrundlagen - kurz: Texte zu Heroldsamt und Adel, in denen sich der spezifische Wissensbedarf des Heroldswesens widerspiegelt. Oft sind diese Texte auch mit jenen identisch, die das »Kompendium des Herolds Sicile« zu den einzelnen Themen enthält.

Wenn eine inhaltliche Eingrenzung der Heroldskompendien als Wissenssammlungen zum Heroldsamt, zu adeligen Zeremonien und zu den Fertigkeiten und Kenntnissen des Heroldsamtes in dessen Umgang mit der adeligen Lebenswelt somit zu greifen scheint, bleibt das Fehlen von Rahmentexten und offensichtlichen Strukturen problematisch. Der allergrößte Teil der Kompilationen verfügt über keinerlei Selbstaussagen zu ihrer Adressierung und Intention. Für deren Rekonstruktion bliebe folglich nur die Analyse des Inhalts der Kompendien. Aber selbst wenn einige auch Traktate enthalten, bei denen es sich explizit um Instruktionen für Herolde und Persevanten handelt ${ }^{38}$ oder als deren Autor sich eindeutig

36 Vgl. Heraudica, personnes, $n^{\circ} 0006$.

37 Es ist nur eine weitere Kompilation dieser Art bekannt (London, BL, Egerton 1644), die in gleicher Weise über einen Prolog und die Nennung ihres Urhebers verfügt. Doch nennt sich dieser allein bei seinem Amtsnamen: Franquevie, humble et petit serviteur, herault de Vallenchiennes (f. 8[bis]r). Der Name Francque Vie für den Stadtherold von Valenciennes ist jedoch über den gesamten Zeitraum von 1367 bis mindestens 1511 belegt, so daß eine nähere Einordnung des Autors momentan nicht möglich ist. Die Handschrift selbst stammt mindestens aus der Zeit nach 1521.

38 Dies ist z. B. beim »Obsequientraktat « der Fall, welcher mit den Worten beginnt: En apres tous heraulx et poursievans doibvent cognoistre comment les obsecques se doibvent faire (Paris, BnF, fr. 23998, fol. 77r). 
ein Herold zu erkennen gibt ${ }^{39}$, so kann dies - so legen Beispiele aus deren weiterer Überlieferung nahe ${ }^{40}$ - nicht ohne weiteres auf die gesamte Kompilation übertragen werden.

Damit bleibt die Eingrenzung der Quellengruppe in Bezug auf deren Intention, Gebrauch und Überlieferung offen. Hinsichtlich der Anlage einiger der Manuskripte ist ohne weiteres zu vermuten, daß es sich hierbei um Textsammlungen für den persönlichen Gebrauch der Herolde gehandelt haben könnte. Doch deuten die beiden Kompendien, die als einzige ebenfalls über Rahmentexte und damit über Selbstaussagen zu ihrem Inhalt verfügen, weitere Möglichkeiten an ${ }^{41}$. Das eine wurde ausdrücklich für einen adeligen Büchersammler zusammengetragen, der zudem selbst auf dessen Inhalt Einfluß nahm. Das andere wurde durch eine Person außerhalb des Heroldsamtes angelegt und war ebenfalls eher an ein adeliges Publikum adressiert.

Hier deuten sich Parallelen zu den Feststellungen Claire Boudreaus zu den traités de blason an, demnach deren Zielgruppe sich im Verlaufe des 15. Jahrhunderts von den Herolden zu den Adligen verschob ${ }^{42}$. Während die Blasonierungstraktate ursprünglich der Unterweisung der Persevanten und Herolde dienen sollten, fanden sie sich spätestens seit der zweiten Hälfte des 15. Jahrhunderts auch im adeligen Milieu wieder, wo sie an Popularität wie an Autonomie stetig gewannen. In ihren verschiedenen Ausprägungen standen sie am Ende vorrangig für den Wissensdrang, die Gelehrsamkeit und die Bibliophilie eines überwiegend adeligen Publikums.

Diese Feststellung muß nicht allein für die Blasonierungstraktate gelten. Möglicherweise ist sie auch auf die Heroldskompendien zu übertragen, umso mehr als diese ebenfalls wichtige Teile der adeligen Lebenswelt zum Thema hatten und das Berufsfeld der Herolde sich in weiten Teilen mit den Interessen des Adels deckte. Es empfiehlt sich daher, die Eingrenzung der Quellengruppe der Heroldskompendien vorrangig unter inhaltlichen Aspekten vorzunehmen, so daß dieser Entwicklung gegebenenfalls Rechnung getragen werden kann.

Wenn Heroldswesen und Adel also durch gemeinsame Interessen verbunden waren, so mußten auch innerhalb der adeligen Tradition Texte und Textkompilationen existieren, die den Bedürfnissen der Herolde entsprachen. Andererseits konnte es auch vorkommen, daß Teile der Heroldskompendien (oder deren inhaltliche Entsprechungen) auch selbständig oder in völlig verschiedenen Zusammenhängen überliefert wurden. So zeichnet sich ein breiter Überlieferungskontext ab, der näher zu strukturieren ist. Es gilt, die verschiedenen Überlieferungszusammenhänge offenzulegen, um am Ende zu einer klaren Abgrenzung der Heroldskompendien als Quellengruppe zu gelangen.

39 Als einer der wenigen sei hier der »Traktat des Toison d'or zu den Wappenminderungen« genannt, siehe unten, S. $85 \mathrm{f}$.

40 Siehe oben, S. 49.

${ }^{41}$ Für das »Kompendium des Ludwig von Brügge« und das »Argentaye-Kompendium« siehe unten, Kap. 3.2.8 und Kap. 3.2.9.

42 Vgl. Boudreau, Traités de blason, Bd. I, S. 33. 


\subsection{Abgrenzung vom näheren Überlieferungsumfeld}

Die im Folgenden zu unternehmende Unterscheidung zwischen Heroldskompendien und anderen, vorwiegend adeligen Textsammlungen bezieht sich nicht auf deren mögliche Besitzer, Adressaten oder Autoren. Diese konnten auch im Falle der Heroldskompendien ebensogut dem Heroldswesen wie dem Adel angehören. Die vorzunehmende Unterscheidung bleibt allein auf inhaltliche Aspekte zu beschränken.

Die Nähe der Interessenfelder der Herolde und des Adels ist dabei in erster Linie den Aufgaben des Heroldsamtes und seiner besonderen Funktion geschuldet. Diese machten die Herolde zu einem Teil der adeligen Kultur und ließen sie insbesondere an der adeligen Wissenskultur partizipieren, deren wesentliche Elemente zu kennen und zu vermitteln den Herolden oblag. Wenn in einem Traktat über die Abhaltung eines Turniers oder eines gerichtlichen Zweikampfes berichtet wird, so kann dies ebenso das Interesse eines potentiell teilnehmenden Adligen gefunden haben wie das eines Heroldes, dessen Aufgabe es war, derlei Veranstaltungen zu beobachten, an deren Ablauf mitzuwirken oder zumindest über diesen Auskunft zu geben. Gleiches gilt für Blasonierungstraktate. Die korrekte Beschreibung der Wappen und die Kenntnis ihrer Bedeutung mußten im gleichen Maße den Adeligen interessieren, der sie trug, wie die Herolde, für deren Beruf dieses Wissen eine Grundvoraussetzung darstellte. Solche Traktate konnten daher zugleich in einem Heroldskompendium überliefert sein, dessen Inhalt über das Amt der Herolde und das ihnen notwendige Wissen über den Adel berichtete, wie in einer Sammlung von Texten, die den Adel über das ritterliche Leben und die adelige Welt informierte. Dementsprechend heißt es im modifizierten Titel eines Traktates über die Farben der Wappen und deren Gleichsetzung in Tugenden und Edelsteinen, wie er in einem offenkundigen Adelskompendium überliefert ist: ce ou en partie qui doit appartenir au regard de noblesse et d'autre part a tous nobles heraulx ou poursuivans ${ }^{43}$.

In erster Linie geht es im folgenden daher auch nicht um die Zuordnung einzelner Traktate, sondern um das Wesen der Kompendien, die diese transportieren. Ein Überblick über die verschiedenen, den Heroldskompendien verwandten Texte und Kompilationen soll es gestatten, einen Eindruck von den vielfältigen inhaltlichen wie textlichen Verflechtungen zwischen beiden Gruppen zu erlangen und die Unterschiede zwischen diesen herauszuarbeiten. Zumindest, soweit dies möglich ist. Denn in einigen Fällen beginnen diese Grenzen zu verschwimmen. Dann geht es darum, die Grenzräume abzustecken.

\subsubsection{Blasonierungstraktate und Wappenbücher}

Den Heroldskompendien eng verwandt sind die Blasonierungstraktate und Wappenbücher, welche oft unmittelbar mit dem Heroldswesen identifiziert werden.

43 Paris, BnF, fr. 2249, fol. 110r-110v. 
Doch haben die Herolde auf diese Traktate, wie auf das Wappenwesen im allgemeinen, keinen Alleinanspruch. Claire Boudreau konnte in ihrer bereits zitierten Arbeit zeigen, wie die Blasonierungstraktate zunehmend auch im Adel und unter Gelehrten Verbreitung fanden, für die sie eigens verfaßt wurden.

Obwohl es sich hier eher nur um eine Reorganisation des »Blasonierungstraktates in Form eines Dialoges «, eines eindeutig dem Umfeld des Heroldswesens entstammenden Textes handelte, wurde der »Prinsault-Traktat« bereits im 15. Jahrhundert häufiger überliefert als dieser selbst ${ }^{44}$. Für den »Blasonierungstraktat in Form eines Dialoges « konnte Claire Boudreau für diesen Zeitraum 20, für den »Prinsault-Traktat« insgesamt 24 Exemplare ausfindig machen ${ }^{45}$. Der Text des letzteren geht dabei wohl mindestens auf das Jahr 1444 zurück. Seine Bezeichnung jedoch erhielt er von einem Exemplar, das Clément Prinsault zwischen 1468-1476 dem jungen Jacques von Armagnac widmete. Hier heißt es:

Combien [...] je ne soye non aseuré que par les escrips de pluseurs approuvés acteurs et maistres anciens, aussi par la direction et frequentacion des heraulx, nobles et autres vaillans nobles hommes en ce expers, desquels mondit seigneur le duc est tresfervent et singulier zelateur, puisse au temps advenir estre informé et parfaitement instruit de l'invencion, notice et blazon des armes, la connoissance desquelles affiert a toute noble personne a laquelle l'ignorance d'icelles vient en grant vilipende, dejection et opprobre 46 .

Diese Widmung ist nicht in allen Überlieferungen erhalten. Doch auch jene Versionen, die über diese nicht verfügen, beginnen in ähnlicher Weise:

A tous roys, ducz, contes, princes, barons, chevaliers, escuyers et toutes manières de gens, nobles et aultres, à qui appartient savoir dire, déterminer et avoir la congnoissance de plusieurs escutz, armes et blasons ${ }^{47}$.

Bestätigt wird diese Adressierung unter anderem durch Art und Ausstattung der diesen Traktat (weitgehend allein) enthaltenden Handschriften. In einem kleinen und handlichen Format auf gutem Pergament gefertigt, verfügten sie meist über eine reiche Ausstattung48. Stellvertretend für andere sei hier der Besitzeintrag einer dieser Handschriften zitiert:

C'est petit livret de blazon est a noble et puissant seigneur monseigneur Tristant de Langhat, seigneur dudit Langhat, Dalmeyrac et de Brassac, baron d'Auroze et de Monclar et viconte de La Mote. Deo gracias ${ }^{49}$.

44 Vgl. BoudreAu, Traités de blason, Bd. I, S. 23. Zu dem sogenannten »Prinsault-Traktat « vgl. ibid., S. 176-191. Eine Version des Textes wurde ediert von DouËT D’ARCQ (Hg.), Un traité de blason.

45 Vgl. Boudreau, Traités de blason, Bd. I, S. 23.

46 Paris, BnF, fr. 5936, fol. 2r-3r.

47 DouËT D’ArcQ (Hg.), Un traité de blason, S. 321.

48 Vgl. für das 15. Jahrhundert unter anderem: Paris, BnF, fr. 2475, fr. 5936, fr. 6129, fr. 14357, fr. 32748; Paris, Institut, 835; Den Haag, KB, 75 J 34.

49 Paris, BnF, fr. 2475, fol. 12v. Darüber hinaus befindet sich auf fol. 12r das Wappen und die Devise der Familie de Langeacs. Bei dem Besitzer handelt es sich um Tristan de Langeac $(† 1501)$, Kammerherr des französischen Königs Karl VIII., vgl. BouILLET, Nobiliaire d’Auvergne, Bd. III, S. 366. 
In einem anderen Exemplar sind auf der Rückseite des Frontispizes, das den französischen König auf seinem Thron darstellt, sowohl das päpstliche als auch das königliche Wappen wiedergegeben. In den jeweiligen Bildunterschriften wurden diese Wappen Papst Innozenz VIII. und dem französischen Königspaar Karl VIII. und Anne de Bretagne zugeordnet ${ }^{50}$.

Der »Prinsault-Traktat « konnte noch als eine übersichtliche Einführung in die Kunst der Wappenblasonierung dienen. Spätere Werke, wie der Wappentraktat König Friedrichs I. von Aragon (†1504), den er zwischen 1501 und 1504 während seines Exils in Frankreich verfaßte, trieben die Theoretisierung des Gegenstandes hingegen so weit voran, daß sie sich in weiten Teilen bereits von der Realität lösten. Ob seiner herausragenden und luxuriösen Ausstattung ist das königliche Original Friedrichs auch weniger als Blasonierungstraktat denn als Kunstobjekt zu betrachten ${ }^{51}$.

Die Einbindung der Kenntnis der Wappen in die adelige Thematik demonstriert nicht zuletzt eine englische Inkunabel aus dem Jahre 1468, die unter der Bezeichnung »Boke of Saint Albans« bekannt ist. Hier heißt es im Titel:

The Treatyse perteyning of Hawkyng, Huntyng, and Fyshyng with an Angle; and also a right noble Treatyse, which specyfyeth of Blasynge of Armys by Julyan Bernes, emprynted at Westmestreby Wynkyn de Worde, the year of th'yncarnation, MCCCCLXXXVI52.

Gleiches wie für die Blasonierungstraktate gilt auch für die Wappenbücher, welche die Blasonierungstraktate oft begleiten. Auch hier zeichnen sich nicht nur Herolde als deren Urheber und Besitzer aus, sondern auch Adlige und Patrizier. Erwähnt seien hier nur die Wappenbücher des Konstanzers Konrad Grünenberg und des André de Ryneck aus Metz ${ }^{53}$.

Dennoch war die Heraldik ein zentrales Element auch des Heroldswesens und lag damit ganz natürlich im Zentrum ihres beruflichen Interesses. Die ersten Traktate $\mathrm{zu}$ den Wappen und deren Blasonierung stammten aus der Feder von Herolden ${ }^{54}$. Mitunter gingen sie hierbei ausführlich auch auf die Geschichte des Heroldswesens ein, die sie eng mit der Entstehung der Wappen verbanden. Wenn

50 Vgl. Paris, BnF, fr. 14357, fol. 1v. Oben das Wappen des Innozenz VIII., unten das französische Wappen, mit der Bildunterschrift: Innocentius VIII Pontifex Maximus / Afitez Joannes Baptista Cibo 1484; unten Carolus VIII, rex Francorum, ANNA Britanniae / regina Francorum / 1489. Letztere Datierung ist inkorrekt, ließ sich Anne de Bretagne doch erst im Dezember 1490 per procura mit Maximilian I. vermählen, bevor sie ein Jahr später, nach der militärischen Invasion der Bretagne durch Karl VIII., die Ehe mit dem französischen König einging. Wappen und Unterschriften wurden später wohl von anderer Hand eingefügt. Das eigentliche Besitzerwappen in der unteren Bordüre von fol. $2 \mathrm{r}$ blieb frei.

51 Vgl. Boudreau, Traités de blason, Bd. I, S. $223 \mathrm{f}$.

52 Juliana Berners, The Boke of Saint Albans. Zur Einordnung dieser Kompilation und ihres Inhalts vgl. zuletzt: GROSs, Hunting, heraldry and the Fall.

53 Zu Konrad Grünenberg vgl. Stillfried-Alcantara, Hildebrandt (Hg.), Des Conrad Grünenberg Wappenbuch, sowie GRAF, Adel als Leitbild. Zum Wappenbuch des André de Ryneck vgl. ausführlich die kommentierte Edition von Jean-Christoph BLANCHARD (Hg.), L'Armorial d'André de Ryneck.

54 Vgl. Boudreau, Traités de blason, Bd. I, S. 130-172. 
diese Texte, Blasonierungstraktate in Verbund mit einem Wappenbuch, dann noch von weiteren, für das Heroldswesen relevanten Traktaten über den Adel begleitet wurden, so stellt sich die Frage nach deren Positionierung zu den Heroldskompendien.

Dies soll am Beispiel eines anderen Traktates, des »Blasonierungstraktates in Form eines Dialoges«, näher erläutert werden. Sein enger Bezug zum Heroldswesen drückt sich bereits in der Anlage des Textes aus, der nach einer kurzen Einführung in die Geschichte der Wappen und des Heroldswesens in einen Dialog übergeht, in dessen Verlauf ein Herold die Fragen eines Persevanten beantwortet. Überliefert ist dieser Text - anders als der »Prinsault-Traktat « - meist im Verbund mit Wappensammlungen, allgemeinen Listen usw. So ist zum Beispiel in einer jüngeren Sammelhandschrift ein Heft eingebunden, das dem verwendeten Papier nach wohl in das letzte Drittel des 15. Jahrhunderts gehört ${ }^{55}$. Hier sind enthalten:

- der »Blasonierungstraktates in Form eines Dialoges «,

- der »Farbentraktat«,

- eine blasonierte Aufzählung der pairs von Frankreich,

- eine Wappensammlung der Wappen der Kaiser und Könige,

- eine Aufzählung der vier Fürsten der Christenheit,

- eine Wappensammlung zu Herzögen und Grafen.

Von dieser kleinen Kompilation existieren noch zwei weitere Überlieferungen, die beide um weitere Texte ergänzt wurden. Einmal um eine »Aufzählung der französischen Bischofssitze « und - von einer zweiten Hand - den Text des »Prinsault-Traktates «56. Ein andermal um einen $»$ Traktat zur Krönung des französischen Königs in Reims « ${ }^{57}$ sowie um eine Gruppe von Wappen aus dem Reich und der Tataren in der abschließenden Wappensammlung.

Der offensichtlich zur Ausbildung der Herolde konzipierte Blasonierungstraktat wurde hier also von diversen Wappensammlungen und Übersichten zu adeligen Hierarchien und zur Landeskunde, teils auch von Texten zum Zeremoniell begleitet, die allesamt im Interesse der Herolde liegen konnten. Doch auch wenn diese Sammelhandschriften einen großen Teil der Inhalte der Heroldskompendien abdecken - das Heroldswesen als eigenständiges Thema kommt hier nicht vor. Diese Textsammlungen erinnern eher an den in Siciles Prolog zwar angekündigten, in der Überlieferung jedoch nicht erhaltenen vierten Teil seines Kompendiums. In dieser Einschränkung zeichnen sie sich vielmehr als eine eigenständige Quellengruppe aus.

Der Bezug zum Heroldswesen ist dann ein anderer, wenn ein Wappenbuch von einem dezidiert dem office d'armes gewidmeten Traktat begleitet wird. In einer Handschrift aus den letzten Jahrzehnten des 15. Jahrhunderts geht der zentralen

55 Vgl. Paris, BnF, fr. 23077, fol. 128-140. Zum verwendeten Papier vgl. PICCARD, Die Wasserzeichenkartei, Bd. IV, Abteilung X, deren Gebrauch vorwiegend in der Zeit zwischen den 1460 und 1480er Jahren nachgewiesen ist.

56 Vgl. Carpentras, Bm, 591.

57 Vgl. Carpentras, Bm, 592. 
Wappensammlung ein Traktat voran, der sich auf nur wenigen Folios mit folgenden Themen auseinandersetzt: Die Ursprünge des Heroldswesens; die drei Stände (mariage, prêtrise, chevalerie); die Schaffung der fünf militärischen Ämter (Konnetabel, Admiral, Marschall, Kapitän, Herold) und deren jeweilige Aufgaben; die Farben und deren Bedeutung; und letztlich ein Auszug aus dem »Traktat des Jehan Erart«, der von der Geschichte und dem Niedergang des Heroldswesens handelt und dessen zeitgenössische Zustände beklagt. Der Traktat schließt mit folgender excuse ab:

Et pour ce, mes treshaulx et puissans et tres excellens princes, seigneurs et barons et vous, mes tres redoubtez et honnourez maistres roys d'armes, heraulx et poursievans, se apres les honneurs des escriptures des hystoires et anchiennes j'ay escript par maniere de remonstrance chose qui ne soit agreable a aulcuns que me vueillies humblement tenir pour excusé et pardonner les faultes. Car je l'ay fait et translaté pour ce que j'ayme de tout mon cueur la tres noble office d'armes et les bons et loyaulx escuiers. C'est notre seigneur qui de sa grace doinst aux princes et seigneurs et a tous ceulx de l'office volenté de y pourveoir tant et si largement que ce soit a l'onneur de toute gentillesce, dudit office et de tous les loiaulx officiers. $A M E N^{58}$.

Im Mittelpunkt dieses Traktates stand das Heroldswesen, begleitet von Ausführungen zur Militärorganisation, der gesellschaftlichen Ordnung und zur Bedeutung der Wappenfarben. Dabei könnte es sich sogar um einen Auszug aus einem Heroldskompendium handeln, in welchem all diese Inhalte als eigenständige Texte verzeichnet sind ${ }^{59}$, zumal der vorliegende Traktat selbst noch einmal in einer leicht veränderten Version in einem Heroldskompendium englischer Provenienz tradiert ist ${ }^{60}$. Doch wie die abschließende excuse des Traktates verrät, sieht dessen Autor seine Leser nicht allein unter den Wappenkönigen und den Herolden, sondern auch und wohl an erster Stelle im Adel, wobei er beide Gruppen getrennt voneinander anspricht.

In der vorliegenden Handschrift folgt ihm eine kurze genealogische Aufzählung der Ahnen der Gräfin von Saint-Pol, womit wohl Jeanne de Bar (1415-1462) gemeint ist, und eine blasonierte Liste derjenigen ihrer Mutter, Jeanne de Ghistelles $(† 1450)$. Diesen ersten 15 Folios schließt sich dann ein über 84 Folios umfassendes Wappenbuch (mit eigenem Inhaltsverzeichnis) an, mit dem die ursprüngliche Foliierung der Handschrift überhaupt erst einsetzt.

Die Frage ist nun, wie dieses Manuskript in Bezug auf die Heroldskompendien einzuordnen ist. Auf der einen Seite geht dem Wappenbuch ein kurzer, aber umfassender Traktat voran, in dessen Fokus das Heroldswesen und für dieses wesentliche Inhalte stehen. Auf der anderen Seite wird aber aus der Anlage der Handschrift deutlich, daß deren eigentliches Kernstück das Wappenbuch darstellt, dem der Traktat mit den beiden Aufzählungen als Prolog voransteht. In seinem Inhalt deutlich eingeschränkt, ist in der vorliegenden Handschrift damit eher ein

58 Paris, BnF, fr. 5228, fol. 13[bis]v.

59 Zum »Burgundischen Heroldskompendium« siehe unten, Kap. 3.2.5.

60 Vgl. Houwen, Gosman (Hg.), Traité d'héraldique. 
Wappenbuch denn ein Heroldskompendium zu erkennen, das sich mit den verschiedenen Aspekten des Heroldswesens und des Adels auseinandersetzt.

$\mathrm{Da} ß$ der auf das Heroldswesen ausgerichtete Hintergrund dieses Traktates dabei nicht von allein auf die ganze Kompilation verweist, belegt ein letztes Beispiel, das bereits zur nächsten Gruppe hinüberführt: Coutances, Bm, 8. Auch hier ist der genannte Traktat mit einem sehr umfangreichen Wappenbuch verbunden. Doch während der Traktat selbst von dem »Bréviaire des nobles« des Alain Chartier und dem »Prinsault-Traktat « eingeschlossen ist, schließt sich dem Wappenbuch noch ein umfangreicher Text zur Falkenjagd an. Spätestens dieser weist dann deutlich über die möglichen beruflichen Interessen der Herolde hinaus.

\subsubsection{Verwandte Überlieferungen im Kontext adeliger Sammelhandschriften}

Der gemeinsame Hintergrund von Herolden und Adel beschränkt sich aber nicht nur auf die Heraldik. Die jeweiligen Interessen, auf der einen Seite berufsbezogen, auf der anderen ständisch, überschneiden sich auch bei Traktaten zu ritterlichen und höfischen Zeremonien, wie bei Abhandlungen zu Rittertum und Adel. Texte zur Kriegskunst, zu Turnieren und zur noblesse entstanden am Ende des Mittelalters in größerer Fülle und fanden vorrangig in den Bibliotheken des Adels ihre Verbreitung. Auch wenn sie dabei in weiten Teilen die Interessen der Herolde berühren, entstammten sie meist der Feder adeliger Autoren. So im Falle der drei für das 15. Jahrhundert bisher einzig bekannten Turniertraktate: Für deren berühmtestes war René d'Anjou (1409-1480) verantwortlich, Titularkönig von Sizilien und Graf der Provence, der diesen um 1450 verfaßte und darin den idealisierten Ablauf einer solchen Veranstaltung wiedergibt ${ }^{61}$. Auf seinen eigenen Erinnerungen beruhten die Darstellungen des Antoine de La Sale (1385/86-1460) in seinem »Traité des anciens et des nouveaux tournois « aus dem Jahre 145962. Und auch der letzte, in der Forschung weitgehend unbeachtet gebliebene Traktat zu den Turniergewohnheiten zu Zeiten des Uterpendragon und des König Artus stammt von einem adeligen Autoren, aller Wahrscheinlichkeit nach von Jacques d'Armagnac, Herzog von Nemours (1437-1477)63. Letzterem sind meist die Schwüre der Ritter der Tafelrunde und ein diesbezügliches Wappenbuch ange$\operatorname{schlossen}^{64}$, ein anderes Mal auch ein Blasonierungstraktat ${ }^{65}$. Doch auch wenn mehrere der Heroldskompendien Texte zu den Turnieren enthalten, findet sich doch keiner der genannten Traktate in deren Kontext überliefert.

Die Übereinstimmungen zwischen den Heroldskompendien und anderen Überlieferungen aus adeligem Kontext blieben dennoch nicht nur auf das Thematische

61 Vgl. AvriL (Hg.), Livre des tournois.

$62 \mathrm{Vgl}$. Antoine de La Sale, Le traité.

63 Der Traktat ist ediert bei SANDOZ, Tourneys. Für weitere Informationen vgl. JEFFERSON, Tournaments.

${ }^{64}$ Der Traktat ist in dieser Weise überliefert z. B. in: Paris, BnF, fr. 1436, fr. 1437, fr. 1438.

65 Vgl. Paris, An, MM 684.1 (Cat. 2446). 
beschränkt. Zwischen beiden Gruppen gab es mitunter auch erhebliche textliche Verflechtungen. So bilden sowohl die »Ordonnanzen zu den gages de bataille in Frankreich « als auch der sogenannte »Empereur-Traktat«, der über die Kaiserwahl und die Voraussetzungen für die Erhebung eines neuen Königtums, Herzogtums etc. Auskunft gibt, begleitet von einigen militärischen Unterweisungen, einen wesentlichen Bestandteil der Heroldskompendien. Ersterer ist in acht, der zweite sogar in 20 von 25 Überlieferungen enthalten. Doch beschränkt sich die Überlieferung dieser Texte nicht allein auf die Heroldskompendien. Beide sind auch im adeligen Kontext weit verbreitet, teilweise auch im Verbund als Einzelüberlieferungen ${ }^{66}$. Auf Pergament geschrieben, reich dekoriert und mitunter mit Miniaturen versehen, verfügten deren Handschriften bisweilen über kostbare Ausstattung. Eines dieser Manuskripte wurde für Franz II., Herzog der Bretagne (1458-1488), angefertigt ${ }^{67}$. Ein weiteres trägt den Besitzeintrag: C'est livre est a messire Jehan d'Appelvoisin, chevalier, seigneur de Thiors et de la Jobetiere68.

Jean d'Appelvoisin war Kammerherr Karls VII. ${ }^{69}$, in dessen näherem Umfeld diese Texte zirkulierten und unter dem beide in eine Handschrift vereint wurden. Darauf zumindest läßt das Kolophon schließen, daß in einigen Exemplaren enthalten ist:

Ce livre, intitulé »Les serimonies et ordonnances appartenants a gaige de bataille fait par querelle " a esté extraict des registres de la court de Parlement et baillé par feu maistre Guillaume Le Turc, en son vivant president en ladicte court, a messire Tristan l'Ermite, chevalier, prevost des mareschaulx de France, ainsi qu'il dit, lequel l'a baillé a monseigneur de Xantraille, mareschal de France, qui depuis l'a donné au roy. Et la, ceste contenue oudit livre comencant Cy apres devise comment et en quantes manieres les princes d'Almaigne sont fait et creez empereurs « a esté baillé au roy par Jehan de la Gardete, escuier, prevoste de l'ostel dudit seigneur qui l'a prins et extrait d'un livre que lui a baillé et donné le mareschal de Savoye ainsi qu'il dit, etc. ${ }^{70}$

Auch in der »Salade« des Antoine de La Sale, die er zwischen 1442 und 1444 für die Erziehung des ihm anvertrauten Johann von Kalabrien, des ältesten Sohnes des René d'Anjou, zusammenstellte, finden sich die beiden Texte eingeschrieben ${ }^{71}$. Für dessen Erziehung, wie er schreibt, versammelte Antoine de La Sale hier alle Arten von bonnes herbes: Texte über die gute Regierung, eine Liste der Geschichtsschreiber und einige Exempla des Valerius Maximus, eine Chronik zum Königreich Sizilien und dementsprechende Genealogien, und eben die beiden genannten Traktate. In gleicher Weise zitiert er die besagten Ordonnanzen auch in seinem Roman »Jehan de Saintré«, wenn sein junger Held von seiner

66 Vgl. Paris, BnF, fr. 19803, fr. 2258; Paris, Arsenal, 4379; Rouen, Bm, 1152.

67 Vgl. Paris, BnF, fr. 2258.

68 Rouen, Bm, 1152, fol. 31v.

69 Jean d'Appelvoisin, aus einer gewichtigen Familie aus dem Poitou stammend, war u.a. Kammerherr Karls VII., vgl. BeAuchet-Filleau, BEAuchet-FilleAu (Hg.), Dictionnaire historique, Bd. I, S. 84.

70 Paris, Arsenal, 4379, fol. 46v.

71 Vgl. Antoine de La Sale, Euvres complètes, Bd. I, S. 208-245. 
Dame des Belles Cousines eine lehrreiche Unterweisung über die gages de bataille erhält 72 .

Eines der einflußreichsten Werke zu Kriegswesen und Kriegsrecht, von dem mehr als sechzig Handschriften und zahlreiche Wiegendrucke überliefert sind und das schon kurz nach seiner Entstehung in mehrere Sprachen übersetzt wurde, ist der »Arbre des batailles « ${ }^{73}$. Er wurde zwischen 1386 und 1389 von dem Benediktiner Honoré Bouvet (1345-1405[?]) verfaßt. Die hier enthaltenen Artikel zu den gages de bataille wie zum Tragen der Wappen finden sich in einigen der Heroldskompendien auch als eigenständige Auszüge kopiert ${ }^{74}$. Welche Stellung der gesamte »Arbre des batailles « für die Ausbildung der Herolde einzunehmen schien, wird in einem der bereits genannten »Blasonierungstraktate in Form eines Dialoges « deutlich, wo der Herold dem Persevanten die Lektüre des »Arbre des batailles « empfiehlt, wenn er etwas über die droits d'armes erfahren will: Or pourra demander ledit poursuivant: Comment aprendray je le droit d'armes? - Je te respons que tu le trouveras en ung livre nommé l'»Arbre des batailles «75.

An den genannten Beispielen dürfte deutlich geworden sein, wie sehr die Interessen der Herolde und des Adels, wie sehr beide Überlieferungen inhaltlich wie textlich miteinander verflochten waren und ineinander übergriffen. Und so ist es nur selbstverständlich, daß es hier Randerscheinungen gibt, in welchen eine eindeutige Zuordnung kaum mehr möglich ist. Denn größere Textsammlungen, die sich (fast) ausschließlich mit dem Adel und dessen Zeremonien auseinandersetzten, konnten in ihrer Zusammensetzung den Heroldskompendien stark ähneln und Texte beinhalten, welche auch aus den Heroldskompendien bekannt sind oder gar das Heroldswesen selbst betrafen.

Dieser Grenzbereich zwischen Textsammlungen aus adeligem Kontext und den Heroldskompendien soll im folgenden anhand einiger Beispiele näher beleuchtet werden. Als erstes soll hierzu eine Handschrift aus der Biblioteca Nacional in Madrid herangezogen werden, in der unter anderem jene Traktate enthalten sind, an denen eben schon die enge Verbindung zwischen diesen beiden Überlieferungskontexten erläutert wurde ${ }^{76}$ :

72 Vgl. Ders., Saintré, Bd. I, S. 61-63.

73 Zum »Arbre des batailles« siehe Honoré Bouvet, L'Arbre des batailles, sowie die kommentierte englische Übersetzung von Coopland (Hg.), The Tree of Battles. Einen praktischen Überblick über die Struktur des »Arbre des batailles« gibt zudem WRIGHT, The Tree of Battles.

${ }^{74} \mathrm{Zu}$ diesen siehe unten, Kap. 6.2.2.2 und 6.2.3.1 (Anhang).

75 Paris, BnF, fr. 1983, fol. 45v. Einen weiteren Beleg gibt ein Ausschnitt aus einem Traktat über die Herkunft und die Aufgaben der Herolde aus einem englischen Heroldskompendium, wo es heißt: Et ne doivent nulz princes ne seigneurs ne juges de noblesce faire jugement d'onneur ne de drois d'armes, en especial en cas de bataille, sans l'oppinion des heraulx et officiers d'armes. Car a eulx appartient d'en parler et de le savoir faire. Et pour ce, tous heraulx et officiers d'armes doivent avoir et estudier le livre de l'»Arbre des batailles", et le »Livre d'onneur « que l'en appelle le "Livre de la Table de Pruce«, en quoy tout l'onneur de noblesce est declairé (London, College of Arms, M. 19, fol. 153r).

76 Vgl. Madrid, BNE, 408 (E 82). 
- der »Arbre des batailles $«$,

- die »Ordonnanzen zu den gages de bataille in Frankreich«,

- der »Empereur-Traktat «,

- der »Blasonierungstraktat in Form eines Dialoges« und ein weiteres, kleines Traktat zu den Wappen,

- eine Wappensammlung mit den wichtigsten königlichen und fürstlichen Wappen,

- mehrere Aufzählungen zu den christlichen Königreichen, den französischen Fürsten, den französischen Bischofsstädten und den Neun Helden.

Diese Handschrift ist offensichtlich aus mehreren Segmenten zusammengesetzt, die alle eng mit den Interessen der Herolde verbunden sind, ohne daß es sich hier um ein Heroldskompendium handelt. Als erstes steht hier der »Arbre des batailles«, gefolgt von den oft gemeinsam überlieferten Ordonnanzen zu den gages de bataille und dem »Empereur-Traktat«. Und am Schluß steht eine Gruppe von Blasonierungstraktaten, Wappensammlungen und Listen, wie wir sie weiter oben bereits kennengelernt haben.

Eine andere Handschrift, die ebenso eng mit den Heroldskompendien verwandt ist, verdeutlicht diese Beziehung unter einer anderen inhaltlichen Ausrichtung. Deren Schwerpunkt liegt auf dem Turnierwesen 77 :

- der »Empereur-Traktat«,

- ein Traktat über die Durchführung von Turnieren nach der alten Manier und zur Rüstung eines Ritters im Turnier, die unter anderem auch im »Kompendium des Herolds Sicile « überliefert sind ${ }^{78}$,

- die Aufzählungen der französischen Bischofsstädte und Könige,

- ein Bericht über die Obsequien des Bertrand du Guesclin,

- fünf kleinere Stücke des Alain Chartier, darunter der »Bréviaire des nobles«,

- eine ausführliche Wappensammlung zu Brabant, Böhmen, Deutschland, Beauvaisis und weiteren französischen Wappenprovinzen sowie den christlichen Königen, den Sarazenen etc.,

- zwei Turnierankündigungen und eine Anleitung »Zum Anbringen der Banner auf den Turnieren«,

- eine Wappensammlung zum Königreich Aragon,

- eine Aufzählung der französischen Herzöge und Grafen,

- und ein kurzes Stück über die Farben in den Wappen und deren Entsprechungen in Edelsteinen und Tugenden, gefolgt von verschiedenen Beispielen für die Blasonierung des burgundischen Wappens in dieser Manier.

Die gleiche Textgruppe ist noch in einer zweiten, leicht veränderten Version überliefert, wo sie am Anfang um eine Aufzählung der Namen von zwanzig Königen und am Ende um einen kurzen religiösen Text zu Adel und Ehre ergänzt wurde ${ }^{79}$. Beiden sind dabei die gleichen textlichen Umstellungen eigen, die nur beim Ko-

77 Vgl. Paris, BnF, fr. 2249.

78 Vgl. Roland (Hg.), Parties inédites, S. 178-183.

79 Vgl. Paris, BnF, n.a.fr. 18326, S. 89-272. 
pieren entstanden sein können, so daß mindestens eine dritte, ebenfalls fehlerhafte Handschrift angenommen werden muß.

Diese Textgruppe, die sich offensichtlich einer gewissen Beliebtheit erfreute, hebt einerseits auf das Turnierwesen ab, wozu sie die gleichen Traktate bringt, wie sie auch in mehreren der Heroldskompendien zu finden sind. Gleiches gilt für den kleinen Text über das Anbringen der Wappen und die ihm vorangehenden Turnierverkündungen ${ }^{80}$. Und auch der $»$ Empereur-Traktat «, der »Farbentraktat $«$ sowie die verschiedenen Listen sind ebenfalls Teil der Kompilationen der Herolde. Doch fehlt hier jegliche Darstellung zum Heroldswesen.

Dies stellt sich in den nachfolgenden Überlieferungen anders dar. Deren erste, die nach 1473 entstanden sein sollte, enthält ${ }^{81}$ :

- den »État de la maison de duc Charles de Bourgogne« des Olivier de La Marche,

- einen Bericht zur Überführung und den Obsequien Herzog Philipps des Guten und der Isabella von York (1473),

- den »Empereur-Traktat«,

- einen Traktat über das den Herolden notwendige Wissen zu den Obsequien adeliger Herren (»Obsequientraktat «),

- eine kurze Geschichte Trojas,

- und, von anderer Hand, eine ausführliche Chronik zur Geschichte Frankreichs zwischen 1400 und 1467.

Der »Obsequientraktat «, der hier unter dem Titel Comment on doit faire obseques de grans seigneurs erscheint, stammt eindeutig aus den Heroldskompendien und wird hier meist unter der Rubrik La magniere coment heraulx et pourssuivans doivent congnoistre des obseques ${ }^{82}$ wiedergegeben. Auf diese Herkunft verweist in der vorliegenden Version immer noch das Incipit, welches unverändert aus der Vorlage übernommen wurde: Heraulx et poursuivans doivent congnoistre comment les obseques se doivent faire. Mais pour ce que plusieurs ne tiennent point de rigle ${ }^{83}$.

$\mathrm{Da}$ nicht nur Traktate mit einem klaren Bezug zum Heroldswesen in derlei Textsammlungen übernommen wurden, sondern auch Texte zu diesem selbst, zeigt eine weitere Handschrift, die nach Katalogangaben aus dem Besitz der Familie de Croy stammt ${ }^{84}$. Sie verdeutlicht die letzte Stufe der hier vorzustellenden Kompilationen, welche die gleichen Traktate zum Heroldswesen wie die Heroldskompendien enthalten konnten. Die Kompilation setzt sich wie folgt zusammen:

- die Beschreibung des »Pas d'armes de l'Arbre d'or « (1468) und des »Pas d'armes de la Dame sauvaige « (1470), beide aus der Zeit Karls des Kühnen, letztere aus der Feder von Olivier de La Marche,

80 Vgl. Paris, BnF, fr. 1968, fol. 163r-164r.

81 Vgl. Paris, BnF, fr. 5365.

82 Vgl. z. B. Paris, BnF, fr. 25186, fol. 102r.

83 Paris, BnF, fr. 5365, fol. 51v.

84 Vgl. Valenciennes, Bm, 776. 
- ein Bericht des Herolds Charolais über den Einzug Karls des Kühnen in Valenciennes anläßlich eines Ordensfestes des Ordens vom Goldenen Vlies,

- ein Bericht über einen Zweikampf zwischen Anthony Woodville und Antoine dem Bastard von Burgund,

- der »Prinsault-Traktat «,

- der »Montjoye-Traktat« zur Geschichte, Krönung, sowie den Aufgaben und Privilegien des obersten französischen Wappenkönigs Montjoye,

- ein Traktat über die richtige Ernährung von Kleinkindern bis zum Alter von fünf bis sechs Jahren,

- ein kurzes religiöses Stück (épître) mit dem Titel »Homme est de brieve vie«, das ebenfalls in den Heroldskompendien überliefert ist,

- der »Blasonierungstraktat in Form eines Dialoges«, gefolgt vom »Farbentraktat « und einer didaktischen Wappensammlung,

- die Aufzählung der Neun Helden,

- mehrere Stücke von Michault Taillevent wie der »Songe de Thoison d'or « und verschiedene Gedichte zur Einnahme von Luxemburg,

- der Epitaph Herzog Philipps des Guten.

Auch hier finden sich damit mehrere Traktate wieder, die auch in den Heroldskompendien überliefert sind und stark an die Inhalte des weitverbreiteten »Burgundischen Heroldskompendiums « erinnern, mit dem die vorliegende Sammlung offenkundig auch ihre Herkunft teilt ${ }^{85}$. Diese Textsammlung konnte ebenso von einem Adligen wie von einem Herold zusammengetragen worden sein. Doch geschah dies wohl eher nach Gelegenheit und Interesse, wofür ebenso die okkasionellen Ereignisberichte vom Anfang wie der Traktat zur richtigen Ernährung von Kleinkindern sprechen, denn nach klaren beruflichen Bedürfnissen. Vielmehr handelt es sich um eine Sammlung privater Natur. Dennoch ist eine besondere Beziehung zum Heroldswesen bzw. zu dessen Kompendien nicht zu übersehen.

Die genannten Beispiele und die Heroldskompendien, dies dürfte deutlich geworden sein, speisten sich zu großen Teilen aus ein und demselben Pool von Texten. Zwischen der großen Gruppe der adeligen Textkompilationen und den Heroldskompendien gibt es eine erhebliche Schnittmenge. Die Heroldskompendien bilden beinahe nur eine Sonderform der Adelskompilationen, die diese nur um ihre eigenen Texte ergänzte, die vor allem aber in einem besonderen professionellen Interesse entstand. Mit der großen Gruppe der adeligen Textkompilationen blieben sie damit auf mannigfache Weise eng verbunden.

Wie prekär die Abgrenzung zwischen den beiden Gruppen sein kann, daß die Grenze kaum mit letzter Gewißheit bestimmt werden kann, soll ein letztes Beispiel zeigen. Fast in gleicher Weise wie ein in Oxford überliefertes Heroldskompendium, mit dem annähernd gleichen Bildprogramm ausgestattet, enthält eine Wiener Handschrift ${ }^{86}$ :

85 Zum »Burgundischen Heroldskompendium« siehe unten, Kap. 3.2.5.

86 Zur »Wiener Kompilation « und zur Verbindung zwischen den Handschriften Wien, ÖNB, 2652 und Oxford, Bodl. Lib., Douce 278 siehe ausführlich noch unten, Kap. 3.2.3.3. 
- den »Blasonierungstraktat in Form eines Dialoges«,

- Auszüge aus dem »Songe du vergier« und aus dem »Arbre des batailles« zu den Wappen,

- eine umfangreiche Textsammlung zum Turnierwesen, d.h. zur Erlernung ihrer Ankündigung durch die Herolde, den ersten Turnieren unter König Artus und einem Traktat »Zu den Aufgaben der Herolde auf einem Turnier à présent«,

- die »Ordonnanzen zu den gages de bataille in Frankreich « und entsprechende Auszüge aus dem »Songe du vergier« und dem »Arbre des batailles«, sowie letztlich eine eigene Version des $»$ Empereur-Traktates«.

Die Textgruppe zu den Turnieren steht darüber hinaus auch mit den Inhalten des »Kompendiums des Herolds Sicile« in enger Verbindung. Aber im Gegensatz zu dem Oxforder Kompendium sind in der »Wiener Kompilation« nicht enthalten: - zwei Suppliken der Herolde an den französischen König,

- der »Obsequientraktat«, der das den Herolden notwendige Wissen zu dieser Zeremonie vermittelt,

- der $»$ Heroldsschwur $\ll$,

- sowie der »Selon les dits-Traktat« über die Einrichtung des Heroldswesens durch Julius Caesar.

Hier fehlen damit genau jene Texte, welche die Oxforder Handschrift gerade zu einem Heroldskompendium machen. Und auch wenn die Wiener Überlieferung wie jene in Oxford einen Persevanten auf ihrem Frontispiz abbildet, handelt es sich hier dennoch um kein Heroldskompendium im eigentlichen Sinne, da sich keiner der hier enthaltenen Texte explizit mit dem Heroldswesen auseinandersetzt.

\subsubsection{Texte zum Heroldswesen in sachfremdem Kontext}

Um das Panorama zu vollenden, sei abschließend noch auf jene Handschriften verwiesen, die Teile der Heroldskompendien bzw. einzelne Traktate in einem unerwarteten, teils völlig gegensätzlichen Kontext überliefern. Noch am Rande der eben genannten Gruppe steht dabei eine Schachhandschrift aus dem Besitz der Familie de Lalaing87. Diese beginnt mit der französischen Übersetzung des Traktates »Échecs moralisés« von Jacobus de Cessolis ${ }^{88}$, gefolgt in einer anderen Hand von einem umfangreichen Traktat in Latein, der verschiedene Stellungen im Schachspiel anhand von Skizzen erläutert. Den Abschluß der Handschrift jedoch bildet - nun wieder in der ersten Hand - ein Traktat, der zu den vorangehenden in scheinbar keiner Beziehung steht. Unter der Rubrik Comment les heraulx furent premierement fondez ist hier der in den Heroldskompendien weit verbreitete »Selon les dits-Traktat« eingetragen, der von den Anfängen der Herolde unter Julius Caesar und von deren Aufgaben und Privilegien handelt. Überraschend stellt im vorliegenden Fall eine kurze Notiz vom Ende des Traktates und damit der Handschrift den scheinbar fehlenden Bezug zwischen den Texten her:

87 Vgl. Paris, BnF, fr. 24274.

88 Vgl. Jacques de Cessoles, Le jeu des eschaz moralisé. 
Notes que tresprouffitable chose est aux poursuivans de sçavoir raconter la »Moralité des eschez". Car c'est ce qui plus les peut introduire et enseigner a leur office faire. Et pour ce je loe a tous poursuivans en armes que souvent y veullent estudier pour leur prouffit ${ }^{89}$.

Denn beim Traktat des Jacobus de Cessolis handelt es sich nicht um einen Schachtraktat im eigentlichen Sinne, sondern um einen Gesellschaftsspiegel, der sich an den Figuren des Schachspieles orientiert. Bemerkenswert und unbedingt zu erwähnen ist dabei, daß die breite Überlieferung des »Selon les dits-Traktat « sich möglicherweise genau aus diesem Zusammenhang zu speisen scheint. Darauf zumindest deutet eine Erwähnung des »Échecs moralisés « inmitten des Textes hin, die so oder ähnlich in fast allen Versionen des Traktates vorkommt:

si comme dist Jaques de Jannes, dont dessus est feite mention et dont lesdits heraulx ont leur commencement, que iceulx heraulx se doivent moult delicter ou devroyent a lire et estudyer es anchiennes nobles hystores et aux beaux exemples qu'on treuve es livres telz qu'en l'»Eschecquier moralizie" ou »Livre de bonnes meurs « et ailleurs ${ }^{90}$.

Daß sich der Text dann von diesen Wurzeln entfernte, dies belegt die zunehmende Entfremdung des Eschecquier moralizie, welcher in verschiedenen Versionen der weiteren Überlieferung zur Moralité des escheffs ${ }^{91}$ oder den Moralités des Egipciens $^{92}$ entstellt wird. Dieser kurze Ausschnitt belegt noch einmal die enge Verbindung zwischen den Themen des Heroldswesens und der adeligen Überlieferung und unterstreicht ein weiteres Mal die Bedeutung auch von gesellschaftsrelevantem Wissen für das office d'armes.

Doch auch dieser letzte inhaltliche Bezug fehlt im folgenden Beispiel. Eine der drei für das 15. Jahrhundert bekannten Überlieferungen des »Briefes des Wappenkönigs Calabre«, in welchem er auf sieben Fragen zum Heroldswesen antwortet, ist in einer Handschrift mit vorwiegend religiösen Texten in lateinischer und französischer Sprache enthalten ${ }^{93}$. Hierzu zählen unter anderem ein AugustinusKommentar, eine Vita der Maria von Ägypten, Abhandlungen über die Taten der französischen Könige, kleinere theologische bzw. kirchen- und heilsgeschichtliche Stücke und ein Traktat über die Osmanen. Einzig der direkt vor dem Brief Calabres eingeschriebene »Débat de honneur « zwischen Hannibal, Alexander und Scipio verweist auf ein ähnliches Themenfeld ${ }^{94}$.

Doch konnten Traktate zum Heroldswesen in einem völlig anderen Kontext auch erst entstehen. Dies ist zumindest bei der Schrift »De origine heraldorum «

\footnotetext{
89 Paris, BnF, fr. 24274, fol. 156rb.

90 Vatikan, BAV, Ottoboni lat. 2257, fol. 4v. Eine kürzere Version findet sich bei RolAND (Hg.), Parties inédites, S. 56: que les morant en champ humainnement et vertueusement, si comme racompte Jacques de Jennes en la moralité des Eschelez. Hier wurde die »Échecs moralisés « jedoch fälschlicherweise dem Jacobus de Voragine (Jacques de Jennes ist eine in den mittelfranzösischen Quellen geläufige Bezeichnung für ihn) zugeordnet.

91 Manning (Hg.), Argentaye Tract, S. 46, Z. 216.

92 Bern, Burgerbibliothek, A 280, fol. CVIv [247v].

93 Vgl. Oxford, Bodl. Lib., Rawl. C 399.

$94 \mathrm{Zu}$ dessen Überlieferung allein in einer Untergruppe des »Burgundischen Heroldskompendiums « siehe unten, Kap. 3.2.5.1.
} 
von Aeneas Silvius Piccolomini der Fall, dem späteren Papst Pius II.95. Dieser gibt vor, in London ein altes Manuskript gefunden zu haben, das von der Gründung des Heroldsamtes durch Dionysius auf dessen Indienfahrt berichtet ${ }^{96}$. Von diesem ausgehend, zeichnet er die Geschichte des Heroldsamtes bis in seine Gegenwart fort. In der Form eines Briefes gehalten und auf das Jahr 1451 datiert, beschränkte sich dessen ursprünglicher Adressatenkreis auf einige wenige Kollegen Piccolominis in der Wiener Reichskanzlei, deren Urteil er seine »humanistische Fingerübung « ${ }^{97}$ aussetzte. Der Text wurde dann jedoch breit überliefert, zumeist in humanistischen Sammelhandschriften. Er fand seinen Weg auch in einige der Heroldskompendien, zumeist durch Übersetzungen ins Deutsche bzw. ins Englische $^{98}$. Dessenungeachtet zeigt der erste, zwischen 1471 und 1475 entstandene Druck des Textes, daß die Auseinandersetzung mit der Herkunft der Herolde auch weiterhin mit einem anderen Interesse gelesen werden konnte, wo er von Piccolominis »De situ et origine Pruthenorum «, »De Liuonia « und »De bello Turcorum et Hungarorum « begleitet wird ${ }^{99}$.

Der vorangehende Überblick hatte zum Ziel, das zeitgenössische Überlieferungsumfeld der Heroldskompendien wie deren enge Beziehungen zu verschiede-

95 Vgl. zu diesem Text die Edition von FüRBETH, »Vom Ursprung der Herolde«, sowie, vor dem Hintergrund eines Vergleiches mit den französischen Herkunftslegenden, MelviLLE, Herkommen.

$96 \mathrm{Zu}$ diesem Herkunftsmythos und dessen Verwendung in dem vorliegenden Traktat vgl. BöNINGER, Dionysius in Indien.

97 FÜRBETH, »Vom Ursprung der Herolde«, S. 438.

98 Für die Überlieferung der beiden deutschen Übersetzungen vgl. ibid., S. 451-454. Für die englischen Übersetzungen, die für eine breitere Rezeption des Textes stehen, als Frank Fürbeth sie unterstellt, seien für das 15. Jahrhundert genannt: Oxford, Bodl. Lib., Ashmole 764, fol. 1r-8r, Douce 271, fol. 63v-72r und London, College of Arms, Arundel 26 (recte 63), fol. 41r-51v. Und auch der Liste der lateinischen Überlieferungen bei FüRBETH, »Vom Ursprung der Herolde «, S. 444-447, sind weitere hinzuzufügen: London, BL, Stowe 668, fol. 3r-5r und BL, Harley 6149, fol. 79r-82r. Der Umstand, daß es sich bei beiden Handschriften um Heroldskompendien handelt, zum einen englischer, zum anderen schottischer Provenienz, sollte die strikte Einschränkung der Überlieferung auf humanistische Anthologien revidieren, die sicher auch daher kommt, daß Frank Fürbeth sich in seiner Suche vor allem der Findbücher zu humanistischen Handschriften bediente (vgl. ibid., S. 444 Anm. 28). Darüber hinaus sei auch noch auf eine teilweise französische Bearbeitung dieses Textes innerhalb des wohl in den 1520er Jahren entstandenen Heroldstraktates des Thomas Isaac, Wappenkönig Toison d'or, verwiesen (Wien, ÖNB, 7223, fol. 143r-165v, und in einer stark korrumpierten Version im »Savoyischen Heroldskompendium «, BnF, fr. 25186, fol. 2[bis]r16r; siehe auch unten, Kap. 3.2.7), sowie auf eine Einfügung dieses Textes in die bis 1478 reichende Fortsetzung der Chronik der Religiosen der Abtei Dunes durch Adrianus de Budt (Chronique d'Adrien de But, S. 211-215), wo der Text Piccolominis ebenfalls der Erläuterung des Heroldswesens dient.

99 Auch dieser Druck sei der von Frank Fürbeth berichteten Liste der Überlieferungen hinzuzufügen: Enea Silvio de Piccolomini (Pius II), De situ et origine Pruthenorum, De Liuonia, De bello Turcorum et Hungarum, De officio et origine heraldorum, Köln: Arnold Terhoernen, zwischen 1471 und 1475 oder um 1472, vgl. darüber hinaus GoFF, Incunabula, Nr. P 745. Exemplare des Druckes sind in Stuttgart und Gotha erhalten, vgl. den Inkunabel-Katalog deutscher Bibliotheken (INKA), Internet: http://www.inka.uni-tuebingen.de/ (Zugriff: 02.03.2011). 
nen anderen Traditionszusammenhängen zu beschreiben. Dabei konnte gezeigt werden, daß die gleichen Themen, wie sie für die Heroldskompendien typisch waren, auch in der adeligen Überlieferung und darüber hinaus präsent waren. Die Heroldskompendien dürfen daher nicht als abgeschlossenes Quellencorpus in einem ausschließlichen Bezug zum Heroldswesen betrachtet werden. Es ist vielmehr zu beachten, daß unter verschiedenen Vorzeichen auch andere Lesergruppen an den gleichen Inhalten, teils gar an den gleichen Texten interessiert waren und daß die Herolde bzw. die Kompilatoren der Heroldskompendien diese wiederum aus anderen Überlieferungszusammenhängen übernommen haben konnten.

Die geläufige Charakterisierung der Heroldskompendien als Textsammlungen, die von Herolden für Herolde verfaßt wurden, kann ob der fehlenden Belege für den überwiegenden Teil der Überlieferung so nicht aufrechterhalten werden. Es ist daher nur möglich, die Heroldskompendien nach inhaltlichen Gesichtspunkten zu definieren. Demnach handelt es sich hier um Kompilationen von Texten, die sowohl ausführlich über das Heroldswesen informieren als auch über adelige Zeremonien, die adelige Welt und deren Zeichen. Sie vermittelten spezielle Fertigkeiten und allgemeine Wissensinhalte, die zur Ausführung des Amtes der Herolde dienlich waren bzw. deren beruflichen Interessen entsprachen. 